\title{
Towards an Advanced Reactor Network Modeling Framework for Fluidized Bed Biomass Gasification: Incorporating Information from Detailed CFD Simulations
}

\author{
Addison K Stark ${ }^{\mathrm{a}}$, Christos Altantzis ${ }^{\mathrm{b}, \mathrm{c}}$, Richard B Bates ${ }^{\mathrm{b}}$, Ahmed F Ghoniem ${ }^{\mathrm{b}}$ \\ ${ }^{a}$ Advanced Research Projects Agency - Energy, United States Department of Energy, Washington, District \\ of Columbia 20585, United States \\ ${ }^{b}$ Department of Mechanical Engineering, Massachusetts Institute of Technology, Cambridge, \\ Massachusetts 02139, United States \\ ${ }^{c}$ National Energy Technology Laboratory, Morgantown, West Virginia 26507, United States
}

\begin{abstract}
Fluidized bed biomass gasification (FBBG) is a promising technology to enable the thermochemical conversion of biomass to drop-in fuels. Fluidized bed reactors are utilized for solid to gas conversion processes due to their ability to provide a high degree of gas-solid contact, fast solid-solid mixing and fast gas mixing within the bed-zone due to solids-induced flow. In many reactor models of fluidized bed gasifiers this has lead researchers to assume that the bed zone can be modeled as a continuously-stirred tank reactor (CSTR). In this work the limitations of this model are analyzed with reactive CFD simulations and an improved reactor network model (RNM) framework based on two-phase theory (TPT) is proposed which is capable of capturing the influence of mixing in the bed-zone on the thermochemical conversion. This new RNM framework employs reactive CFD modelling to supply hydrodynamic information to the RNM. It is shown that this improved RNM framework is able to better capture the formation of large polycyclic aromatic hydrocarbon (PAH) compounds implying that their formation is strongly dependent on the availability of rich zones in the emulsion phase.
\end{abstract}

Keywords: Gasification, PAH, CFD, Reactor Modeling, Fluidized Bed

Preprint submitted to Chemical Engineering Journal

June 3, 2016

(C) 2016. This manuscript version is made available under the Elsevier user license http://www.elsevier.com/open-access/userlicense/1.0/ 


\section{Introduction}

Thermochemical biofuel production via gasification offers a technological option to reduce both the carbon dioxide intensity of transportation fuels and the United States' dependence on imported oil due to the ability to produce drop-in-ready hydrocarbon substitutes for gasoline, diesel and chemical feedstocks. Further, fluidized bed biomass gasification (FBBG) is a promising technology for biomass gasification due to its compatibility with the physical and chemical properties of biomass, such as the high grinding cost and low energy density, which makes the adoption of entrained-flow gasification technology techno-economically impractical.

FBBGs require a bed material with high thermal capacitance and favorable hydrodynamic properties ideally available at a low price. One such ubiquitous material is silica sand, $\mathrm{SiO}_{2}$, for which the fluidization properties are well researched. With its high mass density $\left(\approx 2500 \mathrm{~kg} / \mathrm{m}^{3}\right)$ and nominal particle diameters $\left(100<\bar{d}_{p}<500 \mu \mathrm{m}\right)$ silica sand is classified as a Geldart B particle or a "Sand-like" particle in the well known classification system of Geldart [1,2]. These particles are characterized by ak number of properties [2] which have been captured in Computational Fluid Dynamics (CFD) simulations for different geometry setups $[3,4,5]$ :

1. Small bubbles form at the distributor and grow and coalesce as they rise through the bed.

2. Bubble size increases roughly linearly with distance above the distributor and excess gas velocity, $U_{0}-U_{m f}$.

3. Bubble size is roughly independent of mean particle size.

4. Vigorous bubbling encourages the gross circulation of solids.

It is because of characteristics 1 and 4 , in addition to its high thermal capacitance, that sand is chosen for FBBGs since solids circulation encourages both well-mixed solid and gas-phase environments in the bubbling regime, thus maximizing inter-phase contact in an attempt to achieve overall homogeneity of the reactive environment.

However, due to the tendency of bubbles to grow and coalesce as a function of height (characteristics 1,2 and 3) with increasing the gas flow sand beds shift to slug- 


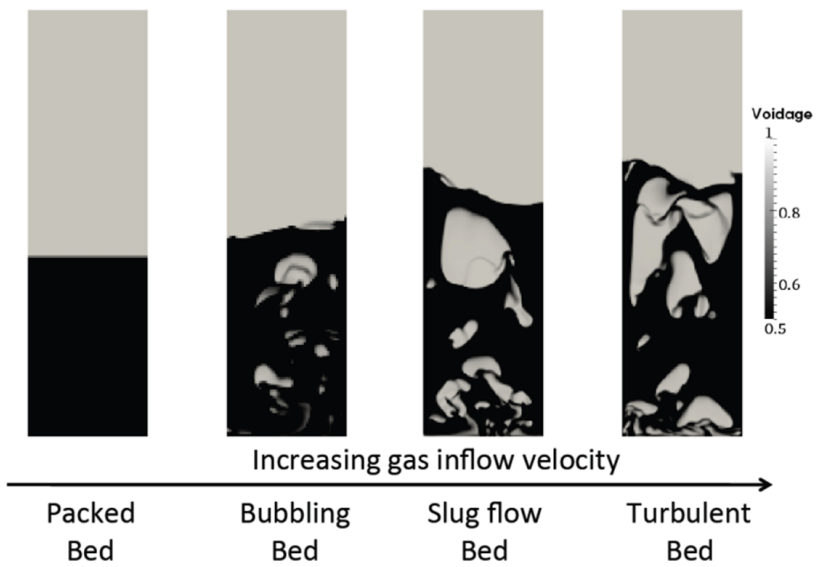

Figure 1: Fluidization regimes of Geldart B particles are strongly sensitive to the gas velocity transitioning through multiple regimes (see [6], from where this figure is reproduced, for further discussion). In the packed bed $\left(U_{0} / U_{m f}<1\right)$ no solids motion occurs and gas flows through the inter-particle voidage. In the bubbling regime $\left(1<U_{0} / U_{m f}<7-8\right)$ solids motion is resultant from gas and bubble motion. In the slugging regime $\left(\left(7-8<U_{0} / U_{m f}<12-13\right)\right.$ flow is characterized by the formation of bubbles on the scale of the bed diameter and a large amount of gas bypassing. Finally, for very fast flow rates $\left(U_{0} / U_{m f}>12-13\right)$ dynamics are dictated by the turbulent motion of solid clusters and voids of various sizes through the bed.

ging and turbulent regimes in which more gas is passed through the bubble phase thus decreasing the overall gas-solid contact within the bed.

The transitions of fluidization regimes for increasing superficial gas velocity are illustrated in figure 1. For gas flows less than or equal to the minimum fluidization velocity $\left(U_{m f}\right)$, the gas-solids momentum exchange is insufficient to cause solids motion and a packed bed is maintained where gas flows through the voidage between the solid particles. With increased gas velocity above minimum fluidization, the bed transitions into a bubbling regime where small bubble formation, growth and coalescence dominates the solid mixing dynamics. As gas velocity increases further, the bubble sizes continue to increase until the largest bubble diameters are of similar size to the overall bed diameter resulting in slugging flow, where bubbles as large as the bed and they lift up the bed entirely. As the gas velocities begin to approach the terminal velocity of the solid material entrainment becomes appreciable for fines and bubble structures 

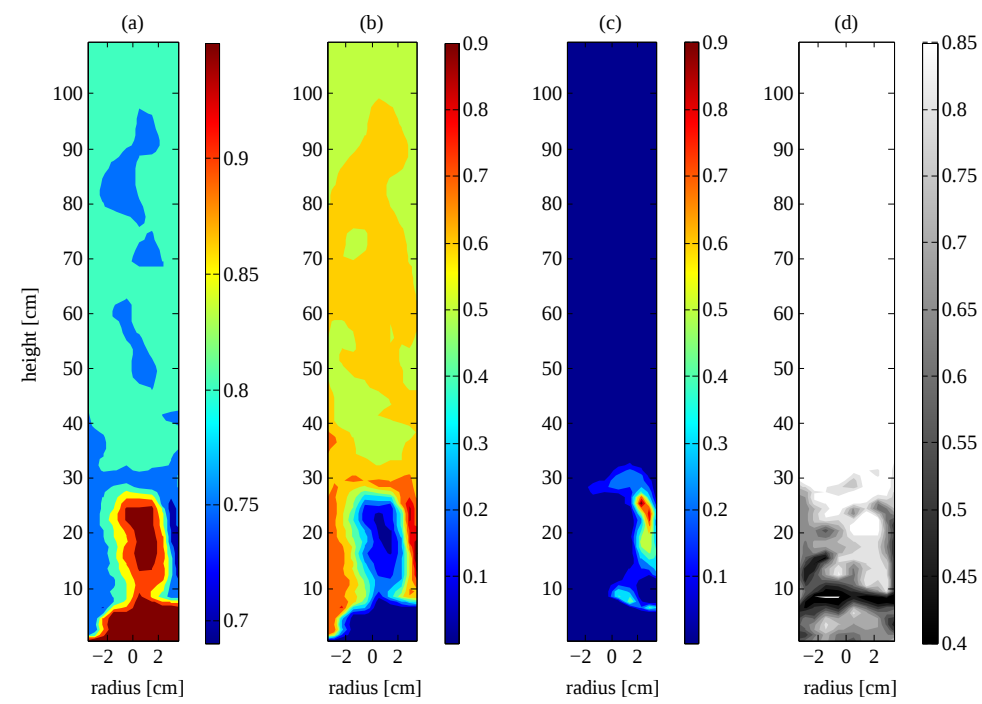

Figure 2: Radial slice of fully reactive CFD of van Paasen and Kiel gasifier as described in this work. In (a) the normalized concentrations of nitrogen (indicative of the air) are plotted. In (b) the normalized concentration of primary tars are plotted. In (c) the normalized rate of devolatilization is plotted and in (d) the gas voidage is plotted.

break down, yielding a turbulent motion of solid clusters and voids of various sizes throughout the bed [2].

The design and optimization of fluidized bed gasification processes is a challenging topic. Spatially and temporally resolved information about gas distribution, devolatilization regions, solid fuel concentrations and circulation are needed in order to identify operational parameters that influence the efficiency of any gasification process. Extracting detailed and reliable experimental data from large-scale reactors is often difficult and expensive in the high temperature and pressure conditions that characterize typical gasifiers. The ever increasing computational power and the development of efficient and reliable numerical models have established CFD simulations as an indispensable tool for understanding the details of gas-solid hydrodynamics, complementing the experimental measurements and hence contributing the optimization of gasifier performance.

In the current study, reactive CFD simulations are employed as a means to explain biomass pyrolysis in a fluidized bed. The geometric setup and the conditions follow 
the experimental work of van Paasen \& Kiel [7]. The instantaneous snapshot of the reactive CFD simulation shown in figure 2 exemplifies both the level of detail aqcuired and the phenomena of gas bypass through the bubble phase. There is a strong correlation between the location of nitrogen (a) and high voidage (d) and a strong negative correlation between the location of these values and the concentration of primary tars (b) and the location of devolatilization (c) itself. It is notable that the devolatilization occurs almost exclusively in the emulsion, and that the devolatilization gasses are most strongly concentrated in the emulsion throughout the bed. In this instance it is clear that the bed zone is far from homogenous and transport can play an important role in controlling the chemical conversion.

Although CFD simulations are regularly employed to study the hydrodynamic behavior of fluidized bed reactors (e.g. $[8,3,4,5])$, extending this modeling framework to realistic reactive conditions is currently limited to simplistic descriptions of the chemistry $[9,10]$ due to the computational challenges involved in coupling the multi-phase flow dynamics with complex chemical conversions occuring in the homogeneous gas phase, at the gas-solid interface and within the solid matrix. Another approach to modeling FBBGs is to employ simplified hydrodynamics in a reactor network model (RNM) which allows for the application of detailed chemistry $[6,11,12]$, but lacks the ability to capture the interactions of fluid flow and chemistry that occur in a dynamic environment such as in a FBBG.

In the work of Stark et al. [11] it was shown that good qualitative and quantitative agreement of predicted gas-phase species can be achieved for major gas species and total tars with the use of a series reactor network model (RNM). However, it was also shown that the prediction of $\mathrm{CO}, \mathrm{CO}_{2}$ and $\mathrm{H}_{2} \mathrm{O}$ concentrations is strongly dependent on catalytic effects of the bed materials on the water gas shift (WGS) reaction as well as the oxidation of $\mathrm{CO}$, and that the tendency of tar species to either crack or grow into polycyclic aromatic hydrocarbon (PAH) compounds is highly sensitive to the local availability of oxygen. If flow conditions are such that gases are able to by-pass the emulsion phase due to large bubbles and slugging then the overall catalytic effect may be reduced and predictions rendered inaccurate. Additionally, if the bed is not wellmixed for both the gas and solids reactions, then devolatilization gas and oxidant may 


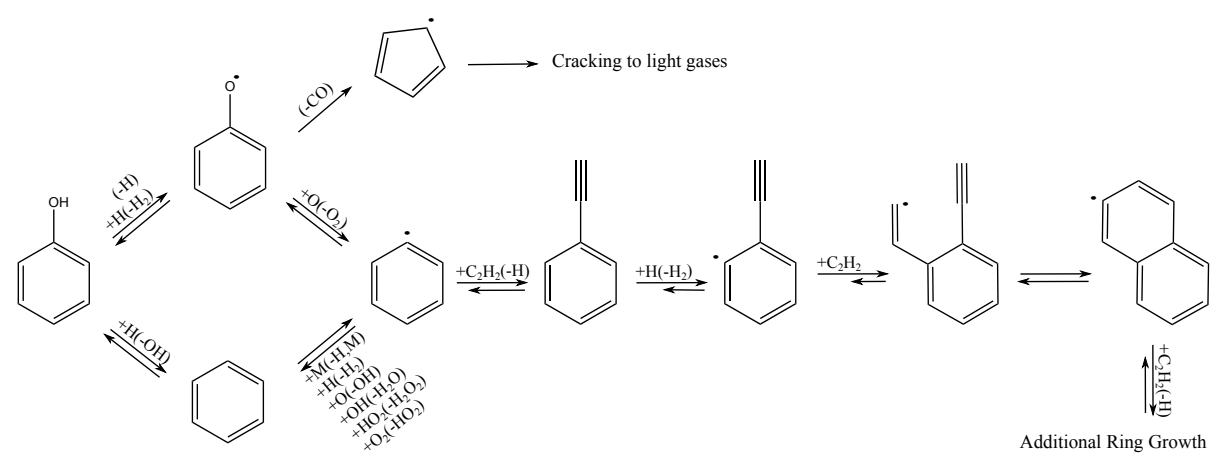

Figure 3: The mechanism of PAH formation from phenol and benzene. The steps from the phenyl radical to the naphthyl radical constitute the Frenklach PAH formation mechanism [13, 14, 15], and the reactions to cyclopentadiene constitute the mechanism of of benzene oxidation proposed by Fuji \& Asaba and Lindstedt $\&$ Rizos $[16,17]$. The relative lengths of arrows connote relative forward and backward rates.

not be uniformly mixed, resulting in locally rich zones thus increasing the likelihood of the formation of PAH compounds. As such, the strong assumptions that both the fluidized bed behaves as a well-stirred reactor and that devolatilization happens uniformly throughout the bed may not lead to accurate predictions since in this ideal limit, oxygen is uniformly available and localized concentration gradients are impossible.

This assumption of a well-stirred gas-phase in the bed zone and the uniform availability of oxygen likely has the strongest influence on the predicted tar composition at the outlet, since the conversion of tars from class 2 (phenolics) to class 3 on to larger PAH compounds (classes 4 and 5) is strongly impeded by the availability of oxygen. This is the case since there are shared hydrogen-abstracted radical intermediates between both the oxidation pathways of aromatic compounds as well as the growth mechanisms.

The mechanism of PAH formation and growth has been a topic of active research in combustion due to its central role in the formation of soot in rich premixed and non-premixed flames $[18,19]$. Fundamental kinetic studies have elucidated the growth mechanism of PAH compounds $[13,20,14,15]$ and have explored the shared initiation step of benzene oxidation and PAH ring growth through the shared radical intermediates $\mathrm{C}_{6} \mathrm{H}_{5} \cdot$ and $\mathrm{C}_{6} \mathrm{H}_{5} \mathrm{O} \cdot[16,17,19]$. Additionally, there have been focused experimental studies on the formation of PAH compounds from biomass sources showing 
that the majority of PAH formation and growth is due to lignin [21, 22]. However, there has yet to be a focused kinetic modeling study of the influence of mixing and the availability of oxygen in determining the total amount of PAH compounds formed in the gasification of biomass in a fluidized bed gasifier.

The generally accepted conversion pathways of phenol and benzene through their hydrogen abstracted radicals $\mathrm{C}_{6} \mathrm{H}_{5} \mathrm{O}_{5}$. and $\mathrm{C}_{6} \mathrm{H}_{5}$. respectively are illustrated in fig. 3 . It is observed that of particular importance in predicting whether PAH formation will occur is the relative availability of $\mathrm{O}_{2}$ and $\mathrm{C}_{2} \mathrm{H}_{2}$, since the phenyl radical $\left(\mathrm{C}_{6} \mathrm{H}_{5} \cdot\right)$ can react with either of these to different results. With increasing ratios of $\mathrm{C}_{2} \mathrm{H}_{2}$ to $\mathrm{O}_{2}$, PAH growth is expected to increase in a non-linear fashion, since as ethynyl groups $(\mathrm{H}-\mathrm{C} \equiv \mathrm{C}-)$ are added it becomes more difficult for the species to be oxidized due to the slow reverse (decomposition) reactions relative to the growth pathway. Further, once the naphthyl radical has been formed, additional rings can be added in an analogous fashion to the first ring addition creating more stable and larger PAH compounds. The relative difficulty of oxidizing $2+$ ring PAH compounds also can have important consequences in reactors where oxygen is not well distributed producing zones of relatively rich conditions where the first ring can be formed, since the resultant PAHs may not be oxidized in a subsequent relatively lean zone due to slower oxidation kinetics.

In this work CFD simulations are employed in order to interrogate the assumptions of a well-stirred gas phase in the bed as well as the uniform devolatilization of biomass throughout the bed as not satisfying these assumptions will necessarily imply localities in the bed where the reactive conditions will be richer than the globally set oxidant-tofuel ratio in the reactor where PAH growth may be favored. The experimental reactor of van Paasen and Kiel[7] used for validation in previous work [11], is simulated and an improved RNM is developed in order to capture the gas bypassing occurring in the slugging regime.

\section{Improved RNM to Capture Gas By-Pass in the Bubble Phase}

A Reactor Network Model consisting of a particle devolatilization model followed by a continuously-stirred tank reactor (CSTR) representation of the bed and a plug 

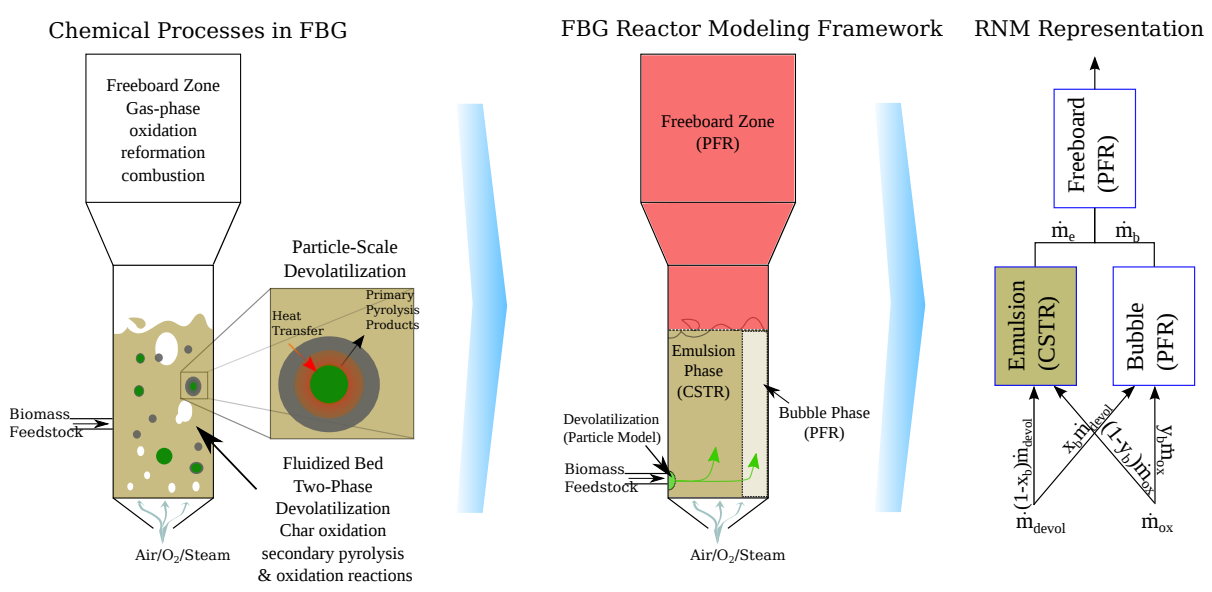

Figure 4: An improved RNM, based on the two phase theory (TPT), where bypassing gas in the bubble phase is modeled as a PFR.

flow reactor (PFR) representation of the freeboard was developed and validated against available reactor data in earlier studies $[6,11]$. It was shown that this simple model is able to capture both qualitative and quantitative trends in the prediction of the gas phase major species as well as light tar fractions. However, it was observed that PAH yields were under-predicted by nearly two orders of magnitude.

Modeling the bed zone as a CSTR is based on strong assumptions that are likely violated at very fast fluidization rates where hydrodynamics are dominated by the formation of slugs, which is often the case in thin and tall research reactors. At fast fluidization $\left(U_{0} / U_{m f}>8\right)$ bubbles can no longer be assumed to be small and vigorous as required for a well stirred zone. Under such conditions, the newly appearing bubbles coalesce quickly to form large slugs through which a significant fraction of fluidization agent bypasses the emulsion phase entirely. Hence, the overall mixing of the devolatilization gases (released in the emulsion) and the oxidant (fluidization agent) decreases. This could potentially have an important effect on the overall rates of a number of reactions, as for example in the case of the WGS reaction, for which the catalytic effect of the bed material was shown to play an important role [11]. Furthermore, insufficient gas mixing due to bypassing leads to an emulsion relatively rich with devolatilization gases compared to the set global oxidant to fuel ratio for the reactor. In 
this work it is hypthesized that this local divergence from stoichiometry could enhance PAH formation and growth.

A modified RNM, capable of capturing the effects of gas bypassing based on the two phase theory (TPT) proposed by Davidson [23] is illustrated in figure 4. Instead of modeling the whole bed as a CSTR, an additional PFR is added in parallel representing the bypassing gas in the bubble phase. In the original formulation of the TPT, it was proposed that all of the excess gas above minimum fluidization would bypass the emulsion through bubbles. Here, it is accepted that with increasing flow-rate conditions, additional expansion in the emulsion is expected along with some of the increased amount of gas flowing through the emulsion [24]. This TPT modeling approach has been applied under the name "Sequential-Based Process Modeling" with considerable success in modeling the gas-phase processes in fluidized bed natural gas combustion [25], volatile organic compound (VOC) photodegradation in a fluidized bed reactor [26] and coal volatile combustion in a fluidized bed reactor [27]. In each of these modeling approaches simple hydrodynamic sub-models of bubble growth and mass transfer between the bubble-phase and emulsion phase were employed to describe the bed geometry and flow characteristics. In the current study, in order to increase the fidelity of the RNM computations, instead of using correlations from literature, we use CFD simulations to extract the necessary parameters for the RNM formulation. CFD offers detailed description of the complicated hydrodynamics and provides quantitative information which can be used as input to the RNM.

A simplified representation of this reactor model is shown in the right schematic in figure 4. In order to fully describe this reactor network we need first to represent the geometry of each of the reactor zones. For the bed-zone the height of each of the emulsion and bubble reactors are given by the time-averaged bed height $H$ of the fluidized bed. Correlations for the bed expansion ratio available in literature $[23,28$, 29] are shown in table 1.

In addition to the bed height, we need to calculate volumes of each of these reactor zones. Given the bed geometry and the calculated bed height, $H$, we know that the total volume of gas in the bed is: 
Table 1: Correlations of bed expansion from literature. $H$ is the observed bed height and $H_{m f}$ is the expanded bed height at minimum fluidization velocity, $U_{0}$ is the superficial gas velocity, $U_{m f}$ is the minimum fluidization velocity, $U_{b r}$ is the average bubble rise velocity (for correlations see Kunii and Levenspiel [2]), $d_{p}$ is the particle diameter, $\rho_{p}$ and $\rho_{g}$ are the particle and gas density respectively.

\begin{tabular}{|c|c|c|}
\hline & Formula & Reference \\
\hline \multirow{3}{*}{$H / H_{m f}=$} & $\frac{1}{1-\frac{U_{0} / U_{m f}-1}{U_{b r} / U_{m f}+U_{0} / U_{m f}}}$ & \multirow[b]{2}{*}{ Johnsson TPT [28] } \\
\hline & $\frac{1}{1-\frac{1}{1+\frac{1.3}{0.26+0.7 \exp \left(-0.0033 d_{p}\right)\left(0.15+\left(U_{0}-U_{m f}\right)\right)^{-.33}}\left(U_{0}-U_{m f}\right)^{-.8}}}$ & \\
\hline & $\frac{1+14.31\left(U_{0}-U_{m f}\right)^{.738} d_{p}^{1.006} \rho_{p}^{.376}}{\rho_{g}^{126} U_{m f}^{937}}$ & Babu Correlation [29] \\
\hline
\end{tabular}

$$
V_{\text {bed }}^{\text {gas }}=V_{e}^{\text {gas }}+V_{b}^{\text {gas }}=\epsilon_{e} V_{e}+\epsilon_{b} V_{b}=\bar{\epsilon}_{b e d} V_{b e d}=\bar{\epsilon}_{b e d} H A_{b e d}
$$

where $V_{b e d}^{g a s}, V_{e}^{g a s} \& V_{b}^{g a s}$ are the volumes of gas in the bed, emulsion and bubble phases respectively. $V_{\text {bed }}, V_{e} \& V_{b}$ are the total bed, emulsion and bubble volumes respectively, and $A_{b e d}$ is the cross-sectional area of the bed. The mean voidage over the bed is given by $\bar{\epsilon}_{b e d}$, while $\epsilon_{e}$ is the void fraction of the emulsion phase and $\epsilon_{b}$ the voidage of the bubble phase. The emulsion phase has been reported to have a voidage approximately equal to that at minimum fluidization conditions for non-reactive flows [2]. However, in the current study, $\epsilon_{e}$ will be calculated directly from CFD in order to capture the additional expansion occurring due to the gas production during solids devolatilization. The bubble phase is assumed to be devoid of solids so we estimate $\epsilon_{b} \approx 1$, implying the bubble wake and cloud zone is considered as part of the emulsion phase. We then get the following linear system:

$$
\frac{1}{V_{\text {bed }}}\left(\begin{array}{cc}
1 & 1 \\
\epsilon_{e} & 1
\end{array}\right)\left(\begin{array}{c}
V_{e} \\
V_{b}
\end{array}\right)=\left(\begin{array}{c}
1 \\
\bar{\epsilon}_{b e d}
\end{array}\right),
$$

which can be solved for the reactor volumes given the emulsion voidage and the average bed voidage at the operating condition of interest. For systems in which there is no 
devolatilization within the emulsion (Fischer-Tröpsch catalyst beds for example) this calculation can be somewhat simplified by assuming that the emulsion phase voidage is equal to the voidage at minimum fluidization. Tabulated data exist for the voidage at minimum fluidization conditions for a number of materials (see for example [2]).

Finally, we need to solve for the mass fluxes of each of the devolatilization yield and the oxidant into the emulsion and bubble phases. Given the air-fuel equivalence ratio (ER) (defined as the operating mass air-fuel ratio over the stochiometric air-fuel ratio) and operating regime, we can calculate both the mass flow rates of the oxidant gas (air, steam, oxygen, etc) and the devolatilization gases from a particle devolatilization model [6]. Then we know from the conservation of mass that

$$
\dot{m}_{d e v o l}+\dot{m}_{o x}=\dot{m}_{e}+\dot{m}_{b}=\dot{m}_{t o t},
$$

where $\dot{m}_{i}$ is the mass flow rate of the gases and the subscripts devol, ox, $e$ and $b$ correspond to the devolatilization gases, oxidant gases, the emulsion phase and the bubble phase respectively. Additionally, if we define $x_{b}$ and $y_{b}$ to be the fractions of the devolatilization gases and the oxidant gases entering the bubble phase respectively, then we can write the following equations:

$$
\begin{aligned}
& \dot{m}_{e}=\left(1-x_{b}\right) \dot{m}_{\text {devol }}+\left(1-y_{b}\right) \dot{m}_{o x}, \\
& \dot{m}_{b}=x_{b} \dot{m}_{\text {devol }}+y_{b} \dot{m}_{o x} .
\end{aligned}
$$

Since we know $\dot{m}_{\text {devol }}$ and $\dot{m}_{o x}$, we must find $x_{b}$ or $y_{b}$ and the rest of the system parameters will fall out naturally. Calculating these values turns out not to be trivial, as information on the distribution of the devolatilizing particles, emulsion phase and bubble dynamics are required. In order to do this, information from CFD studies is used as outlined in the next section.

Given the reactor geometry and the extracted bed height, $H$, the length and volume of the freeboard is calculated directly. Additionally, the gas properties needed to fully calculate the residence time, the mass flow rate, $\dot{m}_{f}$, and the gas density, $\rho_{g}$, at the inlet of the freeboard are directly calculated from the exit of the bed-zone reactors. 
CFD modeling results support the validity of the assumption that the freeboard acts as a PFR, since above the splashing zone little axial mixing is shown to occur and the time-averaged flow is shown to trend towards Hagen-Poiseuille flow.

As a simplifying assumption, this RNM model purposefully neglects cross-flow between the bubble phase and the emulsion phase in order to consider the influence of the first order effects of gas bypassing and to avoid an iterative solution technique. This assumption could lead to errors when a very tall bed zone with slow superficial gas velocities is considered, in which radial mixing and diffusion times are comparably fast relative to the axial gas flow. This level of complexity needs detailed information for the bubbling behavior and can be accomplished with the use of advanced bubble tracking algorithms (e.g. [30]). Such information will be incorporated in future work, by dividing the bed into a number of vertical zones in which the geometrical and massflow calculations are conducted.

\subsection{RNM Chemistry Modeling}

A detailed mechanism ${ }^{1}$ has been proposed by the CRECK modeling group at Politecnico di Milano encompassing the primary pyrolysis, secondary pyrolysis, cracking and oxidation reactions of the devolatilization species of biomass, as well as the oxidation and combustion reactions of the resultant gas-phase hydrocarbon species[31, $32,33,34]$. This chemical kinetic model is applied here as described in previous work [11], where a detailed particle devolatilization model is coupled with the RNM. In the current model, char conversion is neglected as a simplifying assumption in order to focus on the conversion pathways of tar compounds, however future work aims to couple this reactor scale model with a steady-state char conversion model[35]. Previously, the authors showed, by compairing the calculated char residence times relative to its oxidation and gasification kinetics, that char played a relatively minor role in the chemical conversion in the van Paasen \& Keil FBBG and was predominately accounted for by elutriation [11].

\footnotetext{
${ }^{1}$ Available at: http://creckmodeling.chem.polimi.it/
} 


\subsection{RNM Numerical Methods}

The RNM is coded in Matlab 2014a using the open-source matlab toolbox Cantera 2.0 to solve for the themochemical and kinetic parameters of the gas and solid phase materials [36]. The built-in Matlab stiff ODE solver package ode15s is employed to solve the resultant system of ODEs. Further detail of this approach is given in $[6,11]$.

\section{CFD Modeling Framework}

The hydrodynamic processes occurring within a fully reactive FBBG, including solid-solid, gas-gas and gas-solid mixing, are intimately coupled with the thermal and chemical processes occurring in tandem. In order to model these interactions, fully reactive Computational Fluid Dynamic (CFD) modeling is employed. For the description of the hydrodynamics, a multi-phase Eulerian framework is employed where the gas and solid phases are considered as interpenetrating continua. As such, the solid phases are governed by Navier-Stokes type equations with necessary closures describing the inter-particle interactions as well as the interphase momentum. The mass and momentum conservation equations are solved for each of the phases considered (one gas phase and two solid phases) together with a transport equation for the granular temperature based on the Kinetic Theory of Granular Flows (KTGF). In multi-fluid reactive simulations both the gas and solid(s) temperatures must be solved simultaneously to accurately predict the local reaction rates. As such, both gas phase and solid phase energy conservation equations are solved which are coupled through inter-phase heat transfer terms. The energy conservation equations involve the rate of heat release from the reactions in the different phases as source terms. In addition the thermal interaction with the wall boundaries is taken into account. Of particular importance in accurately predicting the dynamics of chemical conversion of the solid fuel in the FBBG is the modeling of inter-phase heat transfer from the gas to the solids. This is done by calculating a heat transfer coefficient between the fluid phase and the $m^{\text {th }}$ solid phase which depends on a Nusselt number correlation (specific for each solid phase) derived by Gunn [37]. The heat transfer correlation provided in [37] considers a specific area-averaged particle domain, although it has been shown that Nusselt and 
Reynolds numbers are related with varying exponent values depending on the local flow conditions [38]. Finally, the solid phases are assumed to be in thermal equilibrium, hence heat exchange between them is not considered. Details about the basic submodels for the modeling of the mass and momentum and energy equations can be found in: (e.g.[39, 40, 41, 3]) and in the supplementary material accompanying this study. In the current section only the details about the chemistry description and the simulation setup are presented.

\subsection{Chemistry Modeling}

Due to the complexity of CFD simulations a premium is put on the application of a simple kinetic model with the ability to capture the major dynamics of conversion. In this study a simplified four reaction drying and devolatilization model is employed, see Table 2, since they play the most important roles in determining the mass flow dynamics of the gas species in the bed zone.

Simplified devolatilization models such as that employed here are developed empirically using the data for specific biomasses under limited conditions. The devolatilization mechanism of di Blasi \& Branca [42] was developed empirically for beech wood under fast $(1000 \mathrm{~K} / \mathrm{min})$ heating rates ideal for fluidized bed conditions and exhibits the characteristically low char fraction predicted using the CRECK devolatilization model in the Lagrangian particle model developed for gasification temperatures (800$\left.1000^{\circ} \mathrm{C}\right)[11]$. Here, this kinetic model is utilized in a shrinking core modeling framework in order to capture the influence of internal heat transfer in addition to devolatilization kinetics in this multi-fluid eulerian framework. This is achieved with an effective devolatilization rate, $k_{e f f}=1 /\left(\frac{1}{k_{k i n}}+\frac{x}{k_{\text {cond }}}\right)$, where the kinetic rate, $k_{k i n}$, is calculated from the local biomass temperature, the conductivity rate is calculated as $k_{\text {cond }} \cong \frac{F o_{c}}{t}=$ $\frac{\alpha_{c}}{\left(R_{p}-r_{c}\right)^{2}}$ where $F o_{c}$ is the Fourier number of the char layer on the particle, $\alpha_{c}$ is the thermal diffusivity of the char layer, $R_{p}$ is the particle radius and $r_{c}$ is the radius of the char-biomass interface in the particle. A fitting parameter, $x$ is employed for each reactor condition considered by minimizing the predicted particle conversion time of the shrinking core particle relative to the detailed lagrangian particle detailed in previous work [6] under equivalent isothermal conditions. In this work the heats of reaction of 
Table 2: Devolatilization mechanism employed for CFD studies.

\begin{tabular}{lrrr}
\hline Reaction & Rate Expression & Source & Rxn. No. \\
\hline Devolatilization E Drying & {$[1 / \mathrm{s}]$} & \\
Biomass $\longrightarrow .3054 \mathrm{H}_{2}+.1854 \mathrm{CO}+.1687 \mathrm{CO}_{2}+.0671 \mathrm{CH}_{4}+.2734 \mathrm{H}_{2} \mathrm{O}$ & $4.379 \times 10^{9} \exp (-152700 / R T)$ & {$[42]$} & $(1)$ \\
Biomass $\longrightarrow 0.246 \mathrm{Tar}_{1}$ & $1.077 \times 10^{10} \exp (-148000 / R T)$ & {$[42]$} & $(2)$ \\
Biomass $\longrightarrow 1.602 \mathrm{Char}$ & $3.269 \times 10^{6} \exp (-111700 / R T)$ & {$[42]$} & $(3)$ \\
$\mathrm{H}_{2} \mathrm{O}_{(\mathrm{l})} \longrightarrow \mathrm{H}_{2} \mathrm{O}_{(\mathrm{g})}$ & $5.13 \times 10^{6} \exp (-87900 / R T)$ & {$[43,44]$} & $(4)$ \\
\hline
\end{tabular}

the primary pyrolysis reactions (1-3) are assumed to be auto-thermal, and the heat of reaction of drying is taken to be the latent heat of vaporization of water $(2257 \mathrm{kj} / \mathrm{kg})$. The authors believe the auto-thermal assumption to be valid since reported biomass pyroysis heats of reaction are variable, with values ranging from slightly exothermic to slightly endothermic (less than an order of $\pm 0-300 \mathrm{kj} / \mathrm{kg}$ ). When compared to the heat of vaporization of moister and the sensible heat of heating the biomass from ambient to reaction temperatures neglecting the heat of pyrolysis is shown to be a vailid assumption [11, 42].

It is not expected - nor necessary - that perfect agreement with experiment will be possible with this reaction set due to its severely limited detail, however these reactions allow for qualitative and quantitative understanding of the temporal and spatial distribution of the major conversion pathways of solid-phase species, informing the development of RNM models where detailed chemistry is employed.

\subsection{Simulation setup}

The simulation setup is based on the experimental work of van Paasen \& Kiel [7]. The authors measured tars of different classes at the exit of a cylindrical gasifier with an expansion step. The $3 D$ simulations conducted in the current study considered a cylinder with the same radius $\left(R_{\text {bed }}=3.7\right) \mathrm{cm}$, constant all along the bed, but with larger height $\left(H_{\text {bed }}=178\right) \mathrm{cm}$ in order to account for the freeboard expansion. The initial static bed height is $\left(H_{\text {static }}=50\right) \mathrm{cm}$ and the initial bed inventory consists only of spherical silica sand particles with density $\rho_{\text {sand }}=2500 \mathrm{~kg} / \mathrm{m}^{3}$ and diameter $d_{\text {sand }}=$ $250 \mu \mathrm{m}$. Air, the fluidizing medium, is supplied uniformly from the bottom boundary at a temperature of $T=1073 \mathrm{~K}$. Biomass spherical particles with $\rho_{\text {bio }}=650 \mathrm{~kg} / \mathrm{m}^{3}$ and $d_{b i o}=1 \mathrm{~mm}$ are fed into the gasifier from a port located $10 \mathrm{~cm}$ above the distributor at 
a temperature of $T=303 \mathrm{~K}$. The pressure inside the reactor is $1 \mathrm{~atm}$. Seven different superficial gas velocities $\left(U_{i n}\right)$ and biomass feeding rates are considered. In all cases the Air-Fuel equivalence ratio is constant and equal to 0.25 . A summary of the conditions considered is presented in table 3 while the details for the different flow cases are presented in table 4.

Uniform inflow gas velocity at constant temperature is specified at the bottom, while a constant pressure outflow is used at the top boundary of the domain. Along the walls, a no-slip boundary condition is used for the gas phase and a partial-slip boundary condition is adopted for the solids phases based on the formulation of Johnson and Jackson [45]. The parameters characterizing the influence of the wall on the solids hydrodynamics are the wall-particle restitution coefficient $e_{w}$ and the specularity coefficient $\phi$. The parameters used in the current study, namely $e_{w}=0.8$ and $\phi=0.005$, are in accordance with the observations presented in $[3,4]$. Dirichlet boundary conditions are employed for the wall temperature. The $3 D$ simulations were conducted in the cylindrical frame of reference and hence the numerical boundary along the centerline was treated according to the formulation of Bakshi et al. [8]. Finally, the parameters involved in the expression for the inter-particle drag model, namely the friction coefficient, $C_{f}$, and the seggregation slope coefficient, $C_{s}$ are 0.1 and 0.3 respectively.

The radial direction is discretized with 12 cells with average $\Delta r=2.5 \mathrm{~mm}$ $10 d_{\text {sand }}$, the axial direction with 700 cells with $\Delta y=2.54 \mathrm{~mm}$ and the azimuthal direction with 12 cells. A non-uniform grid in the radial direction is used in order to prevent the existence of excessively small cells at the center of the domain while maintaining sufficient resolution along the walls. The computational domain is discretized with 100800 cells, with the volume of each cell being $\sim\left(10 d_{\text {sand }}\right)^{3}$, which is the generally acceptable resolution requirement for the Two Fluid Model. Grid sensitivity analyses have been conducted in previous studies for cold flow simulations in bubbling fluidized beds in both rectangular and cylindrical beds with similar particles sizes $[3,4,5]$. Employing higher resolution grids could be potentially problematic since the cell volume would be comparable with the size of the large biomass particles [8].

For the CFD modeling of the operation of a FBBG, the open source code Multiphase Flow with Interphase eXchanges (MFIX) developed by the US Department of 
Energy at the National Energy Technology Laboratory (DOE-NETL) is used [40]. The finite volume method is employed for the spatial discretization of the governing equations on a staggered grid. The velocity components are calculated at the centres of the cell faces, while the scalars are computed at the centres of the cells. The diffusion terms are discretized using a central differencing scheme and the superbee flux-limiter is employed for the convection terms. Both techniques ensure second order accuracy [41]. The numerical technique is based on the SIMPLE (Semi-Implicit Method for Pressure Linked Equations) algorithm [46]. Time integration is accomplished by a first order accurate forward Euler method employing a variable time step which is automatically adjusted to reduce the run time. A detailed description of the numerical implementation is presented in [41].

\section{Results and Discussion}

In the current study, the reactor of van Paasen \& Kiel [7] is modeled using the reactive multi-fluid CFD framework detailed above in order to test the CSTR assumption for the bed zone and to propose an improved RNM representation of the fluidized bed reactor. This particular reactor has been chosen due to the availability of many (though not all) details on the geometry and experimental set-up and run details. This research reactor was operated with air as the oxidant and wood as the fuel.

The focus of these reactive FBBG experiments generally was on the impact of temperature and ER on the overall conversion of solid fuel and the resultant gaseous product distribution. Here, in addition to varying these parameters the impact of superficial gas velocity and fuel particle diameter on the conversion chemistry via the hydrodynamics and mixing is also studied.

In order to quantify the impact of gas bypassing and devolatilization gas mixing with the oxidant within the bed-zone, and to quantify the parameters necessary for the improved RNM, a parametric CFD study has been undertaken for the van Paasen \& Kiel reactor geometry with various feedstock and air flow rates, as summarized in Table 4. These flow conditions were selected to be able to explore both the bubbling regime closer to minimum fluidization velocity (Runs 1-4) and the slugging/turbulent regime 
Table 3: Summary of CFD simulation parameters for van Paasen \& Kiel gas velocity parameteric study.

\begin{tabular}{|c|c|c|}
\hline & Parameter & Value(s) \\
\hline \multirow{8}{*}{ Gasifier Specifications } & Geometry & cylindrical \\
\hline & Diameter $[\mathrm{cm}]$ & 7.4 \\
\hline & Height $[\mathrm{cm}]$ & 178 \\
\hline & Bed Material & Silica sand \\
\hline & Bed Material Diameter $[\mu m]$ & 250 \\
\hline & Bed Material Density $\left[\mathrm{kg} / \mathrm{m}^{3}\right]$ & 2500 \\
\hline & Total Bed Material $[\mathrm{kg}]$ & 1 \\
\hline & Biomass Feed Height $[\mathrm{cm}]$ & 10 \\
\hline \multirow{7}{*}{ Operating Conditions } & Temperature $[K]$ & 1073 \\
\hline & ER [] & 0.25 \\
\hline & Pressure [atm] & 1 \\
\hline & Feedstock Species & Beech wood \\
\hline & Fuel Feedrate $[\mathrm{kg} / \mathrm{hr}]$ & variable (see Table 4) \\
\hline & Feedstock Moisture [\%wt] & 10.2 \\
\hline & Air Feed Rate $[\mathrm{kg} / \mathrm{hr}]$ & variable (see Table 4) \\
\hline \multirow{2}{*}{ Simulation } & Time $[\mathrm{s}]$ & 50 \\
\hline & Time averaged span [s] & $20-50$ \\
\hline \multirow{2}{*}{ Initial Conditions } & Bed Configuration & packed bed material at bottom \\
\hline & Temperature & uniform \\
\hline \multirow{3}{*}{ Thermal Boundary Conditions } & Walls & Isothermal \\
\hline & Distributor Plate (bottom) & Specified gas temperature $(1073 \mathrm{~K})$ \\
\hline & Biomass inlet & Specified biomass temperature (303K) \\
\hline Chemistry Modeling & Heats of Reaction & 0 (isothermal assumption) \\
\hline
\end{tabular}


Table 4: Superficial Gas velocity CFD parametric study for van Paasen \& Kiel reactor [7]. The base-case (1

kilogram biomass per hour) is bolded. The total gas velocity is calculated by taking into account both the flow from the inlet as well as gas released from devolatilization.

\begin{tabular}{lccccccc}
\hline & Run 1 & Run 2 & Run 3 & Run 4 & Run 5 & Run 6 & Run 7 \\
\hline Air feed rate $[\mathrm{kg} / \mathrm{hr}]$ & 0.1313 & 0.175 & 0.3500 & 0.6344 & 0.9516 & $\mathbf{1 . 2 6 8 8}$ & 1.9031 \\
Biomass feed rate $\left[\mathrm{kg}_{\text {wet }} / \mathrm{hr}\right]$ & 0.1034 & 0.1379 & 0.2759 & 0.5 & 0.75 & $\mathbf{1}$ & 1.5 \\
Calculated total gas velocity $[\mathrm{m} / \mathrm{s}]$ & 0.038 & 0.052 & 0.1 & 0.19 & 0.285 & $\mathbf{0 . 3 8}$ & 0.57 \\
Resultant $U_{0} / U_{m f}[]$ & 1.5 & 2 & 4 & 7.25 & 10.875 & $\mathbf{1 4 . 5}$ & 21.75 \\
Temperature $[\mathrm{K}]$ & 1073 & 1073 & 1073 & 1073 & 1073 & $\mathbf{1 0 7 3}$ & 1073 \\
\hline
\end{tabular}

representative of the experimental conditions reported (runs 5-7). As previously noted, the base case (Run 6, bolded) is operating well into a slugging regime. Both temperature $(\mathrm{T}=1073 \mathrm{~K})$ and the specified Air to Fuel Ratio $(\mathrm{A} / \mathrm{F}=0.25)$ are held constant in order to investigate the effect of flow conditions on the conversion chemistry. Only biomass drying and devolatilization reactions are employed (Rxns (1)-(4)) in order to isolate these effects. The rest of the CFD modeling parameters are summarized in Table 3.

For each of these runs the equivalent superficial gas velocity is calculated by considering both the contribution of the gas feed rate and the devolatilization gas from devolatilization, which happens throughout the bed. As such, the superficial gas velocities are estimates of the mean superficial gas velocity in the reactor, since it is increasing with height in the bed due to the devolatilization gas release.

\subsection{Fuel particle segregation and the Devolatilization Zone}

The timescale of mixing of the sand and fuel particles relative to the rate of drying and devolatilization dictates the overall distribution of fuel devolatilization within the reactor and is dependent on both the superficial gas velocity and the particle size. Here, the influence of superficial gas velocity (inlet gas plus devolatilziation gas) on the location of devolatilization reactions is explored.

It is notable that there is strong correlation between the locations of the devolatilization reactions and of the emulsion phase (see chapters $6 \& 7$ in [6]). This is due to the fact that the biomass particles are entrained in the bed material and react within the 
emulsion and not within bubbles. This heterogeneity manifests itself in the distribution of species in the gas phase. In figure 5 the time-averaged spatial distributions of the normalized tar concentrations are plotted with respect to total superficial gas velocity. Here it is notable that there is a high degree of heterogeneity in the gas concentrations in the bed zone, with the preferential bubble pathway having a lean gas mixture and the emulsion exhibiting a rich mixture. This is best illustrated by comparing the tar concentrations in figure 5 with the emulsion distribution shown in figured 8. At the lowest flow-rates the existence of strong devolatilization-zone segregation is apparent, while at increasing flow-rates the tendency of the formation of a torroidal emulsion and devolatilization zone on the walls becomes the dominant characteristic. This heterogeneity lends itself to the necessity to improve the gas-phase reactor model in order to capture the bypassing of gases through the central bubble channel in parallel to the toroidal emulsion zone.

\subsection{Gas Flow and Bypassing in the Bed}

\subsubsection{Calculation and prediction of Bed Height}

As developed in section 2 the bed height, $H$ is a crucial parameter for describing sub-reactors in the RNM framework. From reactive CFD data we calculate the bed height to be the axial point above which the time-average voidage of the cross section is greater than .99 . The time-averaged voidage of the reactor cross-sections can be calculated as a function of height above the distributor plate:

$$
\bar{\epsilon}_{g}(z)=\int_{0}^{2 \pi} \int_{0}^{D_{b} / 2} \bar{\epsilon}_{g}(\vec{r}) r d \theta d r
$$

where $\bar{\epsilon}_{g}(z)$ is the cross-sectional and time-averaged voidage at the height $z$ above the bed, and $\bar{\epsilon}_{g}(\vec{r})$ is the time averaged voidage at the point $r=(r, \theta, z)$. Then we can define the bed height as

$$
0.99 \leq\left.\bar{\epsilon}_{g}(z)\right|_{z \geq H} .
$$

This can be interpreted as the height above-which the voidage is always greater than .99 in a time-averaged sense. 


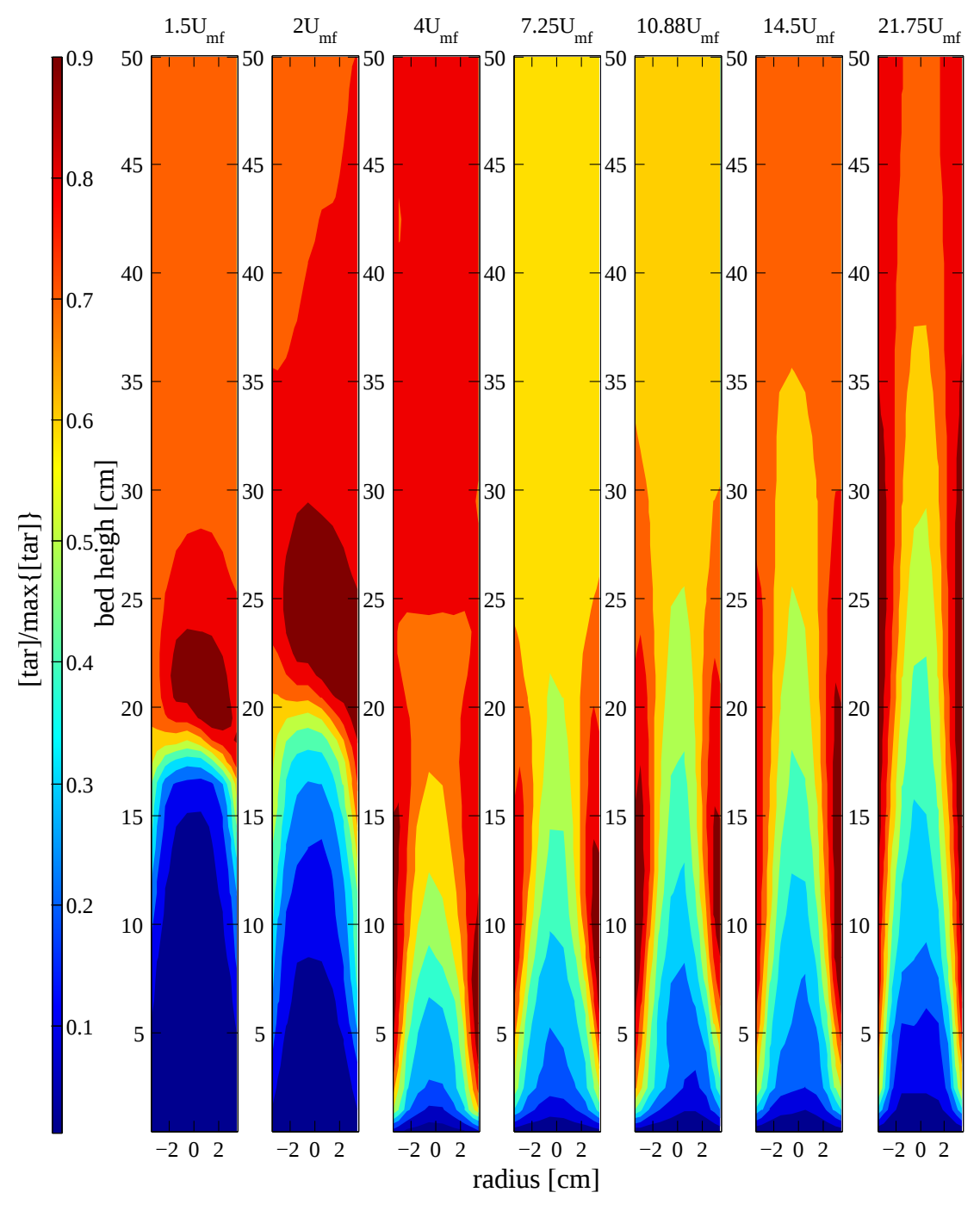

Figure 5: Influence of superficial gas velocity on the time-averaged spatial distribution of devolatilization tars in the lower half of the reactor. 


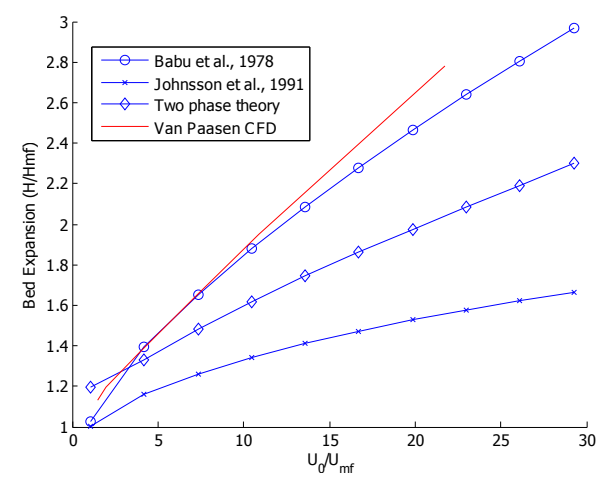

Figure 6: Theoretical (Two Phase Theory [23], Johnsson et al. [28]) and empirical (Babu [29]) correlations for the expansion of the van Paasen \& Kiel [7] reactor geometry relative to superficial gas velocity are compared to reactive $\mathrm{CFD}$ results.

The comparison between the time-averaged bed expansion calculated in the reactive CFD simulations of the van Paasen \& Kiel bed and the three common expressions which are tabulated in Table 1 is shown in fig. 6. The Two Phase Theory (TPT)[23] and Johnsson[28] predictions are theoretical in nature and were developed for non-reactive bubbling beds, as such we find that their predictions are highly divergent from CFD observation with increasing superficial gas velocity, where slugging begins to dominate. The correlation of Babu [29], based off experimental observation of a number of fluidized bed coal reactors, however, appears to give good agreement with calculated bed expansion from CFD. In this study we use CFD simulations in order to calculate the bed expansion parameter for use in the RNM simulations at the specified superficial gas velocities.

\subsubsection{Emulsion and Bubble-Phase Volumes and Average Bed Voidages}

In order to calculate the time averaged gas voidage of the entire bed, the function $\bar{\epsilon}_{g}(z)$ is again integrated from the distributor plate to the time-averaged bed height:

$$
\bar{\epsilon}_{b e d}=\int_{0}^{H} \bar{\epsilon}_{g}(z) d z .
$$

In order to calculate the total volumes of the emulsion- and bubble-phases in the bed, $V_{e}$ and $V_{b}$ respectively, using equation 2 we also need the voidage of the emulsion 
phase. This value is calculated by employing a thresholding value for emulsion equal to 0.8 . According to this definition every part of the bed with voidage below 0.8 is considered to be the emulsion phase, while wherever voidage is higher than the threshold is considered to be a bubble. Then, the average voidage is calculated for the entire volume which is characterized as the emulsion phase.

The average voidage over the bed, as calculated in Equation 8, and the average emulsion voidage, as described above, are plotted versus the superficial gas velocity in fig. 7(a). The increasing average bed voidage, and therefore gas content, is as expected due to the bed expansion with increasing superficial gas velocity. The increase in the emulsion gas content can be attributed to two main drivers. First, with increasing superficial gas velocity we also have increasing biomass feed-rates, as such there is more devolatilization occurring in the emulsion providing a uniform gas release. Additionally, as has been reported by Hilligardt and Werther [24] the flow-rate of gas through the emulsion is not constant with increasing superficial gas velocity as assumed in the origional TFT, but increasing, necessarily causing further expansion of the emulsion.

The difference between the average bed gas content and the emulsion gas content in fig. 7(a) is attributed to the increased volume of bubbles in the bed. Given this, we have sufficient information to calculate the total volumes of the emulsion and bubble-phase volumes $V_{e}$ and $V_{b}$ using equation 2 .

\subsubsection{Flow through Emulsion and Bubble-Phase}

The last parameters required for the RNM developed above is the division of flow of each of the devolatilization and oxidant gases through the emulsion- and bubblephases. These are crucial to establish both of the residence times of the RNM reactors as well as the overall ratio of oxidant and devolatilization gases in each of the RNM reactor zones.

Azimuthally averaged plots of the time-averaged voidage and gas velocity are shown for different inlet gas velocities in fig. 8. It is observed that there exists a toroidal emulsion zone around the walls of the bed, and that gas bypassing occurs through the center of the bed, where bubble coalescence occurs. As the inlet velocity increases bed expansion continues and a wider splashing zone is developed. Additionally, the emulsion 

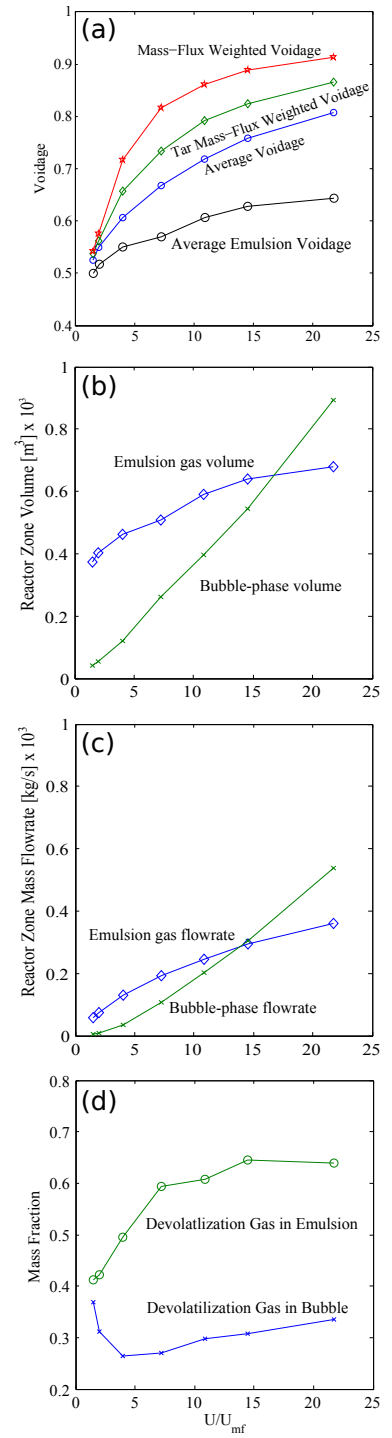

Figure 7: (a) Calculated average bed $\left(\epsilon_{\text {bed }}\right)$, tar-flux weighted bed $\left(\epsilon_{\text {bed, }, \dot{\vec{m}}, \operatorname{tar}_{1}}\right)$ and total gas-flux weighted bed voidages $\left(\epsilon_{\text {bed, }, \dot{\vec{m}}}\right)$ along with calculated average emulsion voidage $\left(\epsilon_{e}\right)$ versus superficial gas velocity. (b) Predicted emulsion and bubble-phase gas volumes. (c) Predicted mass flow-rates of gases. (d) Mass fraction of devolatilization gas in bed zones. 


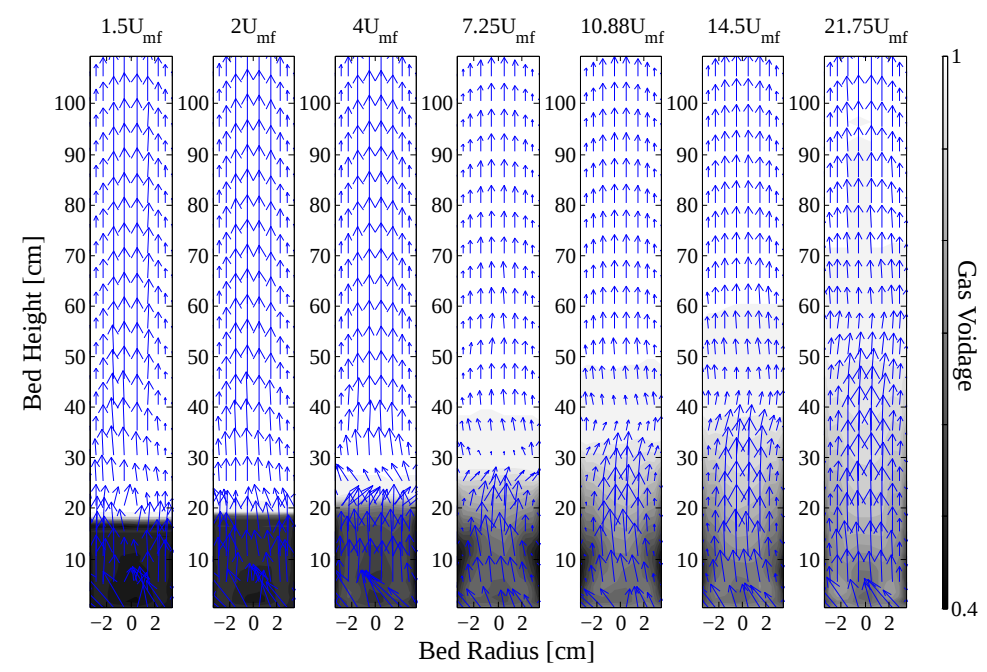

Figure 8: Time-averaged velocity quiver plots are overlayed onto time-averaged voidage distributions for various superficial gas velocities in the van Paasen \& Kiel [7] bed geometry.

phase is stretched higher along the walls as the inner bubble zone increases in radius. Due to the lower gas content, the drag and solids mixing in the emulsion (including flow down the wall) it is observed that the overall upward gas mass-flux is lower through the emulsion zone relative to the preferential bubble path. In all cases, after the gas leaves the bed a Hagen-Poiseuille flow is quickly established, characteristic of a plug flow reactor. Additionally, a transition to Hagen-Poiseuille flow is observed through the center of the bed as the overall flow velocity increases to very high rates lending credence to the shift from a well-stirred bed to a plug flow dominated regime. At low superficial gas velocities $\left(1.5\right.$ and $\left.2 U_{m f}\right)$ it is observed that the gas preferentially travels through a preferential toroid, and the densest emulsion zones are found along the wall as well as in the center. Additionally, at very high velocity $\left(21.75 U_{m f}\right)$ again it is noted that the overall toroidal shape is breaking down and the gas recirculation downward along the wall is breaking down suggesting a decrease in overall bed mixing.

In order to calculate the division of the total gas flow through the emulsion- and bubble-phases we use the CFD simulation results to calculate the gas mass-flux weighted bed voidage with respect to bed height. The mass-flux weighted bed voidage can be used to quantify the breakdown of flow through the emulsion and bubble phase through 
the bed since it is essentially a metric of the effective voidage experienced by the total mass flux through the bed. In the axial direction this is defined as:

$$
\bar{\epsilon}_{g, \vec{m}}(z)=\frac{\int_{0}^{2 \pi} \int_{0}^{D_{b} / 2} \rho_{g}(\vec{r}) \vec{V}_{g}((\vec{r})) \bar{\epsilon}_{g}(\vec{r}) r d \theta d r}{\left.\int_{0}^{2 \pi} \int_{0}^{D_{b} / 2} \rho_{g}(\vec{r}) \vec{V}_{g}(\overrightarrow{(r})\right) r d \theta d r},
$$

where $\bar{\epsilon}_{g, \dot{m}}(z)$ is the mass weighted average bed voidage at height $z$ above the distributor plate, $\rho_{g}(\vec{r})$ is the local gas density, and $\vec{V}(\vec{r})$ is the local gas velocity in the axial direction. This can again be integrated over the bed height,

$$
\epsilon_{b e d, \dot{\vec{m}}}=\int_{0}^{H} \bar{\epsilon}_{g, \vec{m}}(z) d z
$$

yielding the mass-flux averaged bed voidage. This then, can be used to solve for the mass flows through the emulsion and bubble phase with the following linear system:

$$
\frac{1}{\dot{m}_{t o t}}\left(\begin{array}{cc}
1 & 1 \\
\epsilon_{e} & 1
\end{array}\right)\left(\begin{array}{l}
\dot{m}_{e} \\
\dot{m}_{b}
\end{array}\right)=\left(\begin{array}{c}
1 \\
\epsilon_{\text {bed, } \dot{m}}
\end{array}\right) .
$$

In order to solve for the distribution of devolatilization gas between the emulsion and bubble-phase a similar metric can be employed to the mass flux of one of the chemical compounds present in the devolatilization gas flow. Here the concentration of primary tars, $\operatorname{tar}_{1}$, is used.

$$
\bar{\epsilon}_{g, \vec{m}, \operatorname{tar}_{1}}(z)=\frac{\left.\int_{0}^{2 \pi} \int_{0}^{D_{b} / 2} y_{\operatorname{tar}_{1}} \rho_{g}(\vec{r}) \vec{V}(\vec{r} r)\right) \bar{\epsilon}_{g}(\vec{r}) r d \theta d r}{\left.\int_{0}^{2 \pi} \int_{0}^{D_{b} / 2} y_{\operatorname{tar}_{1}} \rho_{g}(\vec{r}) \vec{V}(\vec{r} r)\right) r d \theta d r},
$$

where $y_{\operatorname{tar}}$ is the mass fraction of $\operatorname{tar}_{1}$ (or any tracer species). As before this weighted voidage can be integrated as a function of bed height, yielding the effective voidage experienced by the devolatilization gas:

$$
\epsilon_{b e d, \dot{\vec{m}}, \operatorname{tar}_{1}}=\int_{0}^{H} \bar{\epsilon}_{g, \vec{m}, \operatorname{tari}}(z) d z .
$$

Finally, this tar-mass-flux weighted bed voidage can be used to solve for $x_{e}$ and $x_{b}$ the fraction of devolatilization gas traveling through the emulsion and bubble phases respectively by solving the following system: 


$$
\frac{1}{\dot{m}_{\text {devol }}}\left(\begin{array}{cc}
1 & 1 \\
\epsilon_{e} & 1
\end{array}\right)\left(\begin{array}{l}
x_{e} \\
x_{b}
\end{array}\right)=\left(\begin{array}{c}
1 \\
\epsilon_{\text {bed, }, \dot{m}^{\prime}, \operatorname{tar}_{1}}
\end{array}\right) .
$$

Now we can solve the RNM given spatially resolved voidage, density, velocity and concentration data from CFD. The calculated values for each of the averaged bed voidages are plotted in fig. 7(a). At each superficial gas velocity the trend of $\epsilon_{\text {bed, }}>$ $\epsilon_{b e d, \vec{m}, \operatorname{tar}_{1}}>\epsilon_{b e d}$ makes intuitive sense since it is expected that the total mass flux of gases preferentially travels through a high voidage zone of the bed, which has a higher voidage than the bed on average, and the tars formed predominately in the emulsion, so $\epsilon_{b e d, \dot{m}, \operatorname{tar}_{1}}$ is necessarily lower than $\epsilon_{b e d, \dot{\vec{m}}}$. Also, as expected, in all cases the total voidage is going up due to bed expansion.

\section{Predictions of Improved RNM}

By using the methodology outlined in the previous section we can post-process CFD simulations to build a RNM able to capture more complex bed mixing dynamics. In order to explore the influence of the total superficial gas velocity on the RNM parameters we explore the influence of the variable flow conditions outlined in Table 4. Additionally, given the calculated RNM geometries under hot reactive conditions we also explore the influence of variable temperature at each flow condition by varying the bed temperature from $973 \mathrm{~K}$ to $1273 \mathrm{~K}$ in $50 \mathrm{~K}$ increments.

\subsection{RNM Geometry and Flow Characteristics}

Figure 7(b-c) shows the calculated bed geometry and flow characteristics with respect to the varied superficial gas velocity. The emulsion phase zone volume is observed to be increasing more slowly than the bubble zone indicating that, while there is increasing flow through the emulsion phase with increasing velocity, the majority of this gas instead travels through the bubble phase. This is corroborated in the right plot where it is observed that with increasing superficial gas velocity the amount of flow through the bubble phase is found to be increasing faster than that through the emulsion phase. This has been shown to be the case experimentally with an estimated one-third of the excess gas flow found to travel through the emulsion [24, 2]. Above 
$14 U_{m f}$ it is observed that more than $50 \%$ of the total flow is through the bubble phase, and above $17 U_{m f}$ the volume of the bubble phase is found to be more than $50 \%$ of the total bed volume.

Increasing superficial gas velocity directly impacts the distribution of devolatilization and oxidant gases in the bed zone. In Figure 7(d) the calculated mass fractions devolatilization gas in each reactor zone is plotted versus the operating superficial gas velocity. With higher superficial gas velocity it is observed that an increasing degree of gas segregation occurs, resulting in richer conditions in the emulsion phase than in the bubble phase. The effect is very pronounced at lower superficial gas velocities with the leanest bubble conditions occurring at $4 U_{m f}$. This is likely due to the transition from exterior bubble paths close to the devolatilization zone at lower superficial gas velocities to a central preferential bubble path at $4 U_{m f}$. As the superficial gas velocity increases the solids mixing rate continues to increases and devolatilization happens more uniformly improving the distribution of devolatilization gases.

Given the geometric and mass flow configurations shown in Figure 7(b-c) the influence of varying temperatures at each of these flow conditions on the residence times in the bed and freeboard zone is considered. hese residence times are plotted as contours for varying bed temperatures and inlet flow conditions in Figure 9. At low flow rates it is observed that the temperature has a very small effect on both the bed and freeboard residence times, which are much more sensitive to the flowrate at this low regime (since the residence time scales as $1 / U_{0}$ ), however at larger flow rates where the influence of the flow-rate decreases it is observed that with increasing temperatures the influence on the residence times is lessened. This is due to two effects. First is that of the lower gas density at higher temperatures, second, especially in the bed zone, is the increased gas expansion due to primary tar and hydrocarbon cracking to lighter gases, thus increasing the total molar flow rate.

\subsection{Comparison of RNM predictions with experiment}

In order to assess the impact of capturing devolatilization/oxidant mixing in the bed-zone on the overall reactor conversion the reactor predictions from previous work [11] are compared to the modified reactor predictions here for the base case (case 6). 

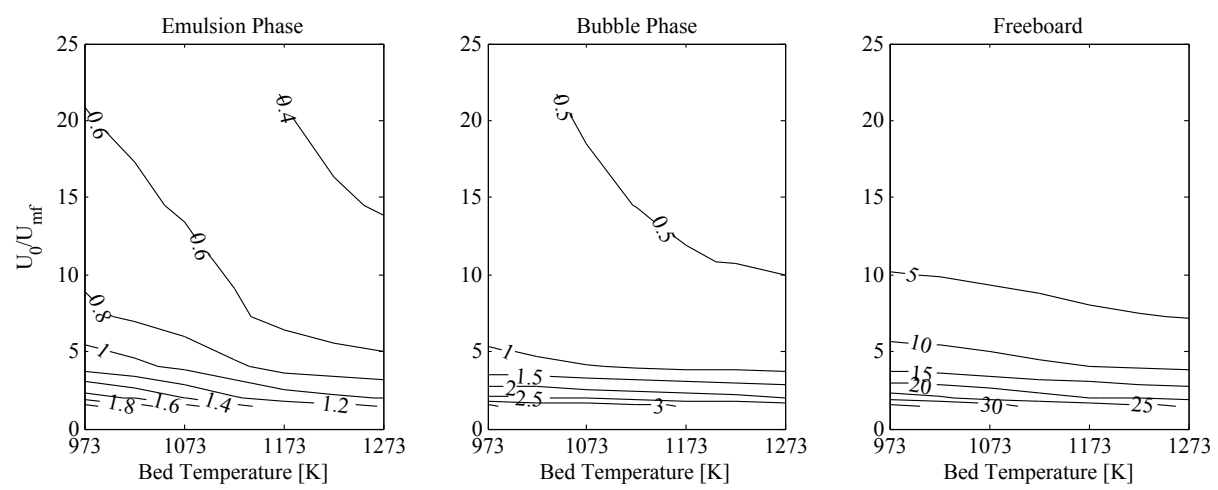

Figure 9: Calculated gas residence times in the bed and freeboard sections of the reactor are plotted as contours of both the bed temperature and flow conditions.

In Figure 10 the tar-class predictions for the simple RNM and the improved RNM are compared with the experimental data from van Paasen and Kiel. It is notable that the predictions of Class 2 and 3 tars are differ only slightly between the RNM and improved RNM. This is as expected since their oxidation and steam reforming reaction kinetics are relatively fast at these operating temperatures, while in the class 3 tar prediction it is notable that benzene is still rather recalcitrant, though slightly higher class 3 tars predicted implying a more favorable environment in the emulsion for their formation. Importantly, it is observed that the predictions of PAH compounds, Class 4 and Class 5 tars are increased at each temperature, and at the lowest temperatures by an order of magnitude where their formation kinetics are very slow. This is indicative that capturing the heterogeneous gas distribution within the bed zone is crucial in order to predict PAH formation and growth. It is notable that the predictions are still 1-2 orders of magnitude short of the recorded experimental measurements. This could still be because the emulsion phase is assumed to be well-distributed and that devolatilization occurs throughout the emulsion in this model. As demonstrated in Section 4.1 devolatilization rarely occurs this uniformly and there likely exists very rich zones where devolatilization gas concentrations are near pyrolysis conditions allowing for free formation of PAH compounds. In order to capture this the bed zone likely needs to be further subdivided in order to capture the richest areas. This possibility is further considered in future work. 

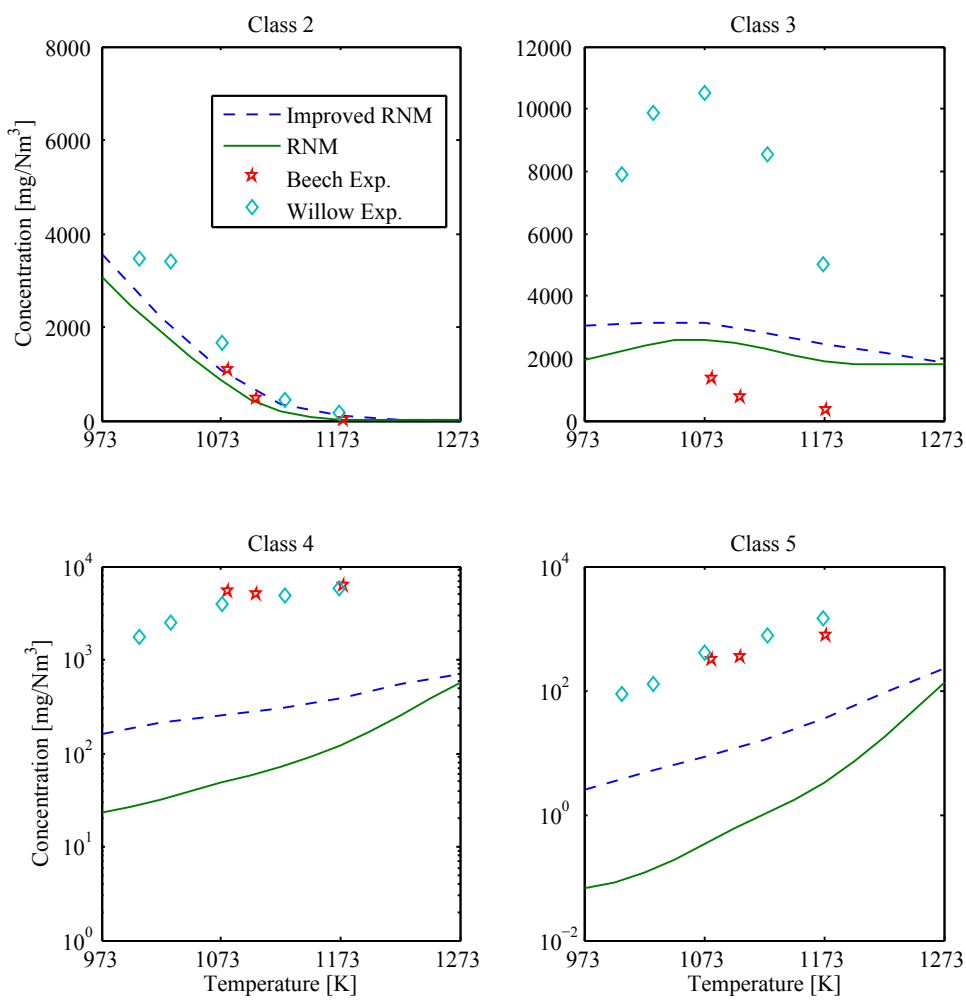

Figure 10: Comparison of RNM configuration tar species predictions with the van Paasen \& Kiel reactor under reactor conditions $\mathrm{ER}=0.25, U_{0}=14.5 U_{m f}$. 
The predictions of major gas species are also affected by bubble bypassing, though not as severely as that of the tar concentrations. In Figure 11 the predicted concentrations of major gas species are plotted for the base case reactor conditions. It is observed that the predictions of hydrogen and carbon monoxide are slightly affected at lower temperatures. The divergence is larger for water and carbon dioxide. With increasing temperature each of the predictions converge. This convergence is likely due to the faster kinetics at higher temperatures, so the resultant gases from the bedzone, when well-mixed in the freeboard, are able to more quickly approach the global equilibrium values. Interestingly the methane concentrations are slightly lower at each temperature. This is due to the increased amount of oxygen available in the freeboard zone due to bypassing in the bubble phase. Early on the methane is then oxidized (along with other hydrocarbons and light tar compounds) this is likely directly contributing to the increased predicted concentrations of water and CO. Previous work by the authors has also shown a strong catalytic influence of the bed material on the major species concentrations via the water-gas shift and $\mathrm{CO}$ oxidation reactions [11]. Lack of catalytic activity on the gas bypassing through bubble phase could also explain the small variation observed in figure 11.

While improved predictions of PAH formation are observed by including this improved bed model capturing oxidant bypassing in the bubble-phase, further investigation of these effects is undertaken in the next section (Section 5.3) in order to quantify the effects of mixing on the chemical conversion.

\subsection{Influence of devolatilization gas and oxidant distribution in the bed on tar chem-} istry

Fluidized bed reactors are employed due to their ability to create a large degree of mixing and contact within the bed-zone between the solid phases, the gas and the solid phases as well as within the gas-phase. This is particularly important in FBBG operation since the availability of oxygen plays an important role as to whether primary devolatilization tars are oxidized to smaller target gasses such as $\mathrm{CO}$ and $\mathrm{H}_{2}$ or react with other aromatic compounds and unsaturated hydrocarbons and grow into PAHs.

As discussed in section 4.1, the solid reactions, in particular drying and devolatiliza- 

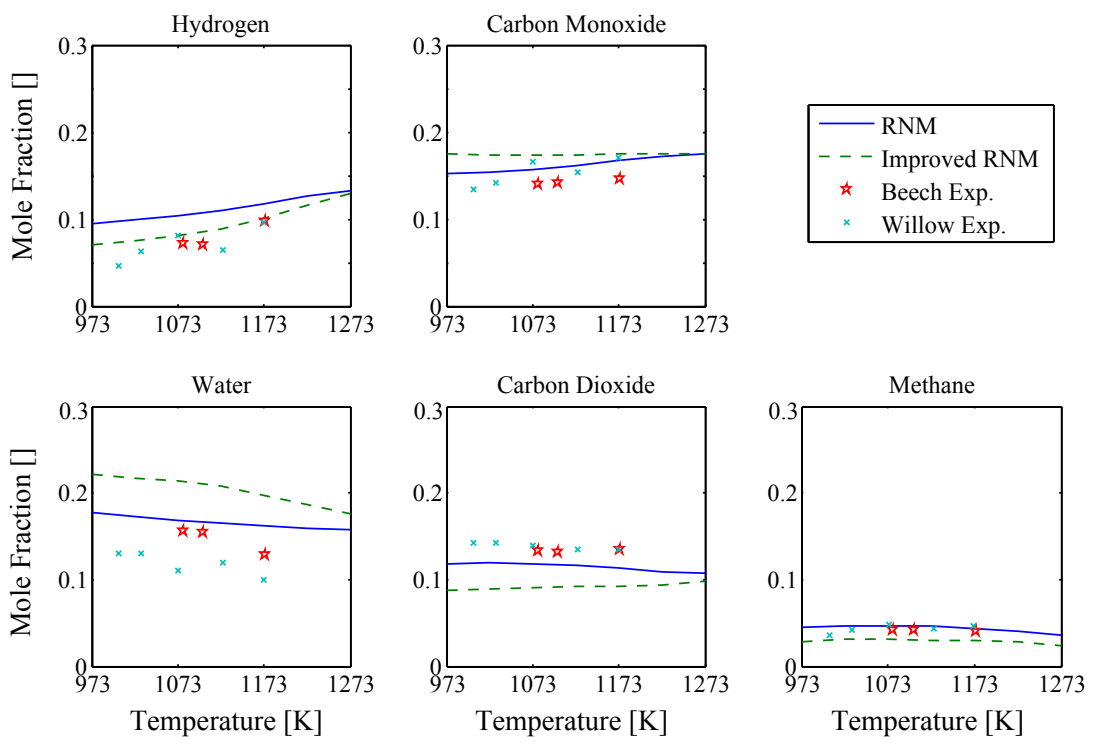

Figure 11: Comparison of RNM configuration major species predictions with the van Paasen \& Kiel reactor conditions $\mathrm{ER}=0.25, U_{0}=14.5 U_{m f}$.

tion, occur within the emulsion phase and under these operating conditions this zone is highly concentrated near the fuel inlet. As such, if there is significant gas-bypass through the bubble phase as quantified by the devolatilization gas mass fraction in Figure 7(d), these devolatilization zones operate at relatively rich conditions with air-tofuel ratios well below the set operating condition (i.e. in a reactor where the global A/F is set to 0.25 these zones could operate at conditions $<<0.25)$. Under these extremely rich conditions in the emulsion phase it is expected that PAH growth would occur more freely in the emulsion, increasing the average tar molecular weight and shifting the speciation of the tar up to larger PAHs. Due to the recalcitrance of these species, once they have been formed then they are not likely to be cracked and oxidized in the bed or freeboard zone.

Two devolatilization gas and oxidant mixing extremes are compared in Figure 12. At one extreme (blue lines) the devolatilization gas is assumed to be released solely into the emulsion (the CSTR). Then the gas bypassing in the bubble is comprised solely of the oxidant, and the remainder of the flow through the emulsion. At the other extreme (green lines) the devolatilization gas and the oxidant are assumed to be uniformly 

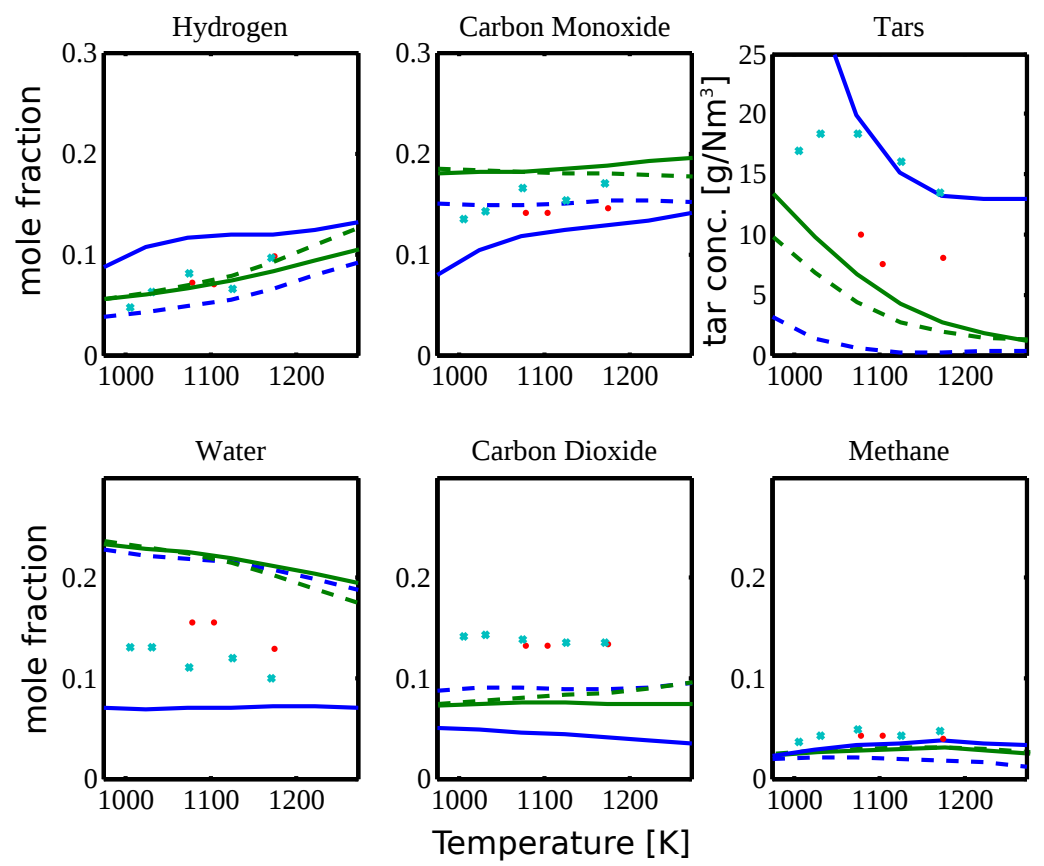

Figure 12: Major gas species (mole fraction) and total tars $\left(\mathrm{g} / \mathrm{Nm}^{3}\right)$ are plotted with respect to temperature for the base van Paasen case (Run 6 in Table 4). The blue squares are for willow and the red dots are beech. The solid lines are the species concentrations at the exit of bed entering the freeboard, and the dashed lines are the predicted species concentrations at the exit. The green lines are where the devolatilization gases and oxidants are distributed evenly through the emulsion and the bubble reactor, while the blue lines are for the case where the devolatilization gases are assumed to be released solely in the emulsion phase. 
mixed at the inlet both to the emulsion (the CSTR) and the bubble phase (PFR). At the inlet to the freeboard (the exit of the bed, solid lines) it is observed that there are very different concentration profiles dependent on these mixing assumptions. In particular the influence on the amount of tar entering the freeboard is readily apparent, where devolatilization gasses are released solely in the emulsion it is observed that due to lack of oxygen much more primary tars are evolved and enter the freeboard than when oxygen is present.

Interestingly, however, when the exit of the freeboard is considered (dashed lines) there are more total tars predicted under the uniformly mixed conditions than under the poorly mixed condition. This is likely due to the fact that under the poorly mixed extreme a large amount of oxygen is available through the whole freeboard allowing for additional oxidation reactions to occur to the smaller tars and hydrocarbons. This is evidenced by the decreased amount of methane predicted under these conditions, which shows a high degree of oxidation relative to the inlet to the freeboard and the exit, while under the well-distributed extreme shows no reduction, but perhaps an indistinguishable increase. This bed then acts like a gasifier allowed to run in a rich condition in the bed with a secondary air injection into the freeboard. Thus, while using the same amount of oxidant, improved exit concentrations are achieved with respect to the total amount of tar and methane present.

In Figure 13 the total predicted tar concentrations from the bed are plotted as contours with respect to the bed operating temperature and the bed flow-rates. It is observed that for an even distribution of devolatilization and oxidant gases into the emulsion and the bubble phase, the total tar production is nearly uniformly decreasing with respect to temperature with a minor uptick at high temperatures and low flow rates. This is due to the growth of larger class 4 and 5 tars given the sufficient residence time and high temperatures necessary for their growth. Additionally, an overall decrease in total tar concentration is observed with decreasing flowrates at temperatures below $1200 \mathrm{~K}$. Here, due to the longer residence times there is continued cracking and oxidation of class 2 and 3 tars occuring, however the temperature is too low for significant PAH growth to class 4 and 5 tars.

For the case where the bypassing gas in the bubble phase consists solely of air with 

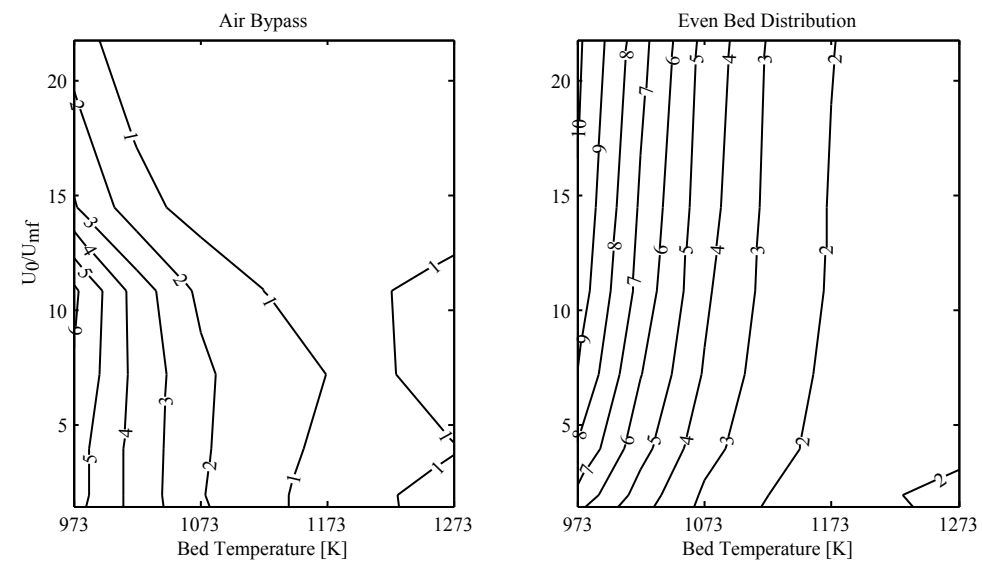

Figure 13: Total predicted tar concentration at the outlet $\left[\mathrm{g} / \mathrm{Nm}^{3}\right]$ of the reactor for two mixing assumptions (1) air by-pass and (2) evenly distributed devolatilization gases in the bed zone.

no devolatilization gas it is observed that there are uniformly fewer tars predicted at the exit for all operating conditions. This is due to the fact that in this assumption of lack of mixing much more oxygen is present in the freeboard allowing for an overall reduction of the total tar amount specifically through cracking and oxidation reactions of class 2 and 3 tar compounds through the length of the freeboard. While the temperature trends are similar with decreasing tars at higher temperatures, it is observed that the uptick at higher temperatures is expanded to higher gas flow-rates than for the even bed distribution, this is due to an increased amount of PAH compounds present (class 4 and 5 tars).

It is observed that the overall tar species distribution changes under these different mixing conditions. Figure 14 shows contours of the mass fraction of the tars at the exit for each tar class proposed by Milne and employed by van Paasen \& Kiel [47]. For the case of having well distributed devolatilization and oxidant gases at the inlet to the emulsion and the bubble phase we observe the expected temperature trends at each temperature, a decreasing amount of class 2 tars, an increasing, and subsequently decreasing, amount of class 3 tars and exponentially increasing amounts of class 4 and 5 tars at elevated temperatures.

For the case of pure air by-passing however, the uniform trends observed for the 
Air Bypass $(\mathrm{xe}=0)$
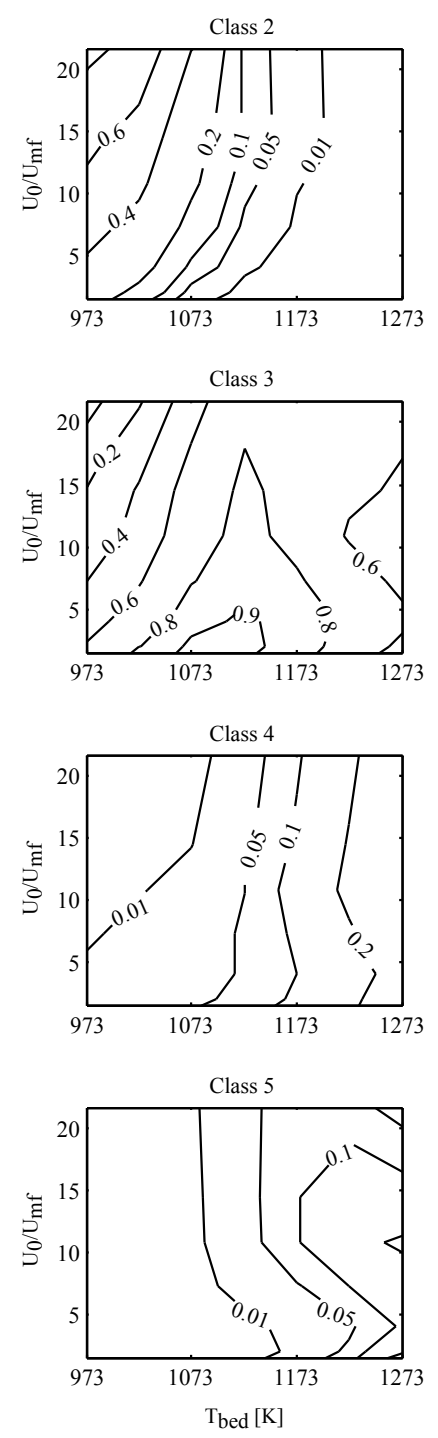

Well Distributed Devolatilization
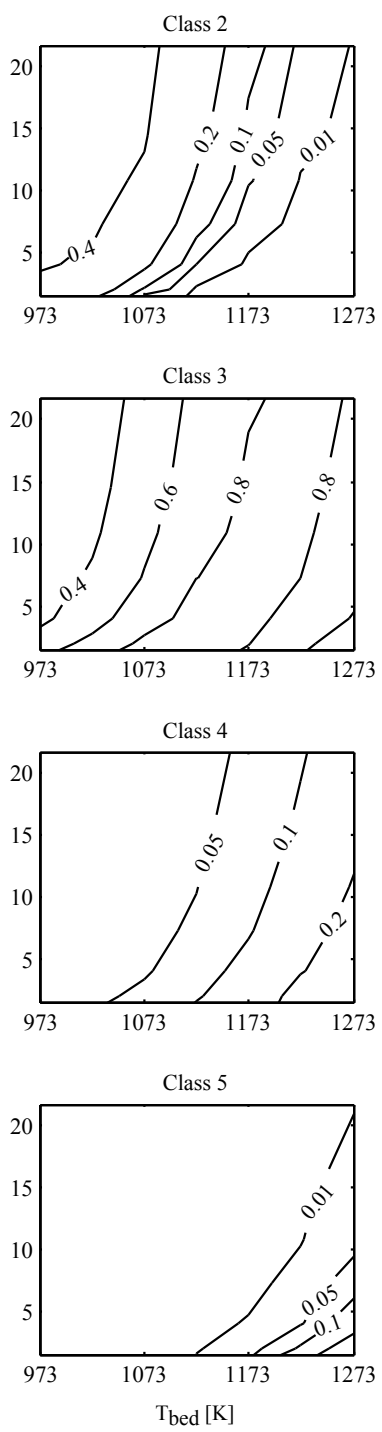

Figure 14: The influence of temperature and superficial gas velocity on tar speciation. The mass fractions of each tar class of the total amount of tar is plotted against reactor bed temperatures and flow rates. 
well-distributed mixing case break down. Here it is also observed that class 2 tars show a uniform temperature dependence at all flow conditions it is only at the fastest flowrates and lowest temperatures where they make up an appreciable fraction of the tars at the exit. This is primarily due to the short residence times where there is insufficient time for the tars to fully oxidize in the freeboard or to grow into PAH compounds. For class 3 tars, it is observed that their peak prevalence is shifted to lower temperatures than is observed in the well distributed case. Additionally, it is seen that from 1100$1200 \mathrm{~K}$ there is a negative dependence of the predicted fraction of class 3 tars on the overall flow-rate. Increased amounts of PAHs (class 4 and 5 tars) are observed for all operating conditions and especially so for faster flow rates under the air bypass conditions.

This last observation, that larger PAH compound fractions are predicted at higher flow-rates, is likely due to the fact that with increasing flow-rates a larger fraction of the oxygen is bypassing the emulsion due to a larger volume fraction of the bubble phase (as shown in figure 7(b-c)), and as such the local ER in the emulsion is necessarily less than the global operating ER of the bed as a whole. As such, in this relatively rich area the primary tars, in the absence of oxygen, are able to form small PAH compounds (class 4 tars) in relative abundance since the competing oxidation pathways are unavailable with decreased oxygen. Then in the freeboard, while there is then sufficient oxygen to consume much of the excess class 2 and 3 tars as observed in figure 12, the light PAHs that were formed in the rich emulsion are able to continue to grow larger since they become relatively recalcitrant to cracking and oxidizing.

\section{Conclusions}

In this work the influence of superficial gas velocity on the solid and gas mixing rates in the bed zone of a fluidized bed reactor are investigated with reactive CFD simulation of a bench-scale fluidized bed gasifier. An improved RNM is developed which is capable of capturing the resulting reactor heterogeneities and resultant transport limitations. This RNM utilizes reactive CFD simulation to calculate the geometric, mass flow and concentration parameters describing the flow in the bed zone. 
It is shown that this improved RNM is able to better predict the formation and growth of large PAH compounds, implying that their formation is strongly dependent on the availability of rich zones in the emulsion phase which cannot be described by a simple CSTR assumption for the bed zone. Finally, it is shown that the improved RNM has little influence on the predicted syngas species concentrations $\left(\mathrm{CO}, \mathrm{CO}_{2}, \mathrm{H}_{2}, \mathrm{H}_{2} \mathrm{O}\right.$, and $\mathrm{CH}_{4}$ ) implying that these are not as sensitive to the bed conditions and approach equilibrium in the freeboard zone.

\section{Acknowledgment}

The authors gratefully acknowledge BP for sponsoring this project. This research was supported in part by an appointment to the National Energy Technology Laboratory Research Participation Program, sponsored by the U.S. Department of Energy and administered by the Oak Ridge Institute for Science and Education.

\section{References}

[1] D. Geldart. Gas Fluidization Technology. Wiley-Interscience, 1986.

[2] D. Kunii and O. Levenspiel. Fluidization engineering. Butterworth-Heinemann, 1991.

[3] C. Altantzis, R.B. Bates, and A.F. Ghoniem. 3d eulerian modeling of thin rectangular gas-solid fluidized beds: estimation of the specularity coefficient and its effects on bubbling dynamics and circulation times. Powder Technology, 270,Part A:256-270, 2015.

[4] A. Bakshi, C. Altantzis, R.B. Bates, and A.F. Ghoniem. Eulerian-eulerian simulation of dense solid-gas cylindrical fluidized beds: Impact of wall boundary condition and drag model on fluidization. Powder Technology, 277:47-62, 2015.

[5] A. Bakshi, C. Altantzis, R.B. Bates, and A.F. Ghoniem. Study of the effect of reactor scale on fluidization hydrodynamics using fine-grid cfd simulations based on the two-fluid model. Powder Technology, 299:185 - 198, 2016. 
[6] Addison K. Stark. Multi-scale chemistry modeling of the thermochemical conversion of biomass in a fluidized bed gasifier. PhD thesis, Massachusetts Institute of Technology, 2015.

[7] S. V. B. van Paasen and J. H. A. Kiel. Tar formation in a fluidised bed gasifier. Technical Report ECN-C-04-013, Energy Research Center of the Netherlands, 2004.

[8] A. Bakshi, C. Altantzis, and A.F. Ghoniem. Towards accurate three-dimensional simulation of dense multi-phase flows using cylindrical coordinates. Powder Technology, 264:242-255, 2014.

[9] S. Gerber, F. Behrendt, and M. Oevermann. An Eulerian modeling approach of wood gasification in a bubbling fluidized bed reactor using char as bed material. Fuel, 89(10):2903-2917, 2010.

[10] Q. Xue, D. Dalluge, T.J. Heindel, R.O. Fox, and R.C. Brown. Experimental validation and cfd modeling study of biomass fast pyrolysis in fluidized-bed reactors. Fuel, 97(0):757-769, 2012.

[11] A.K. Stark, R.B. Bates, Z. Zhao, and A.F. Ghoniem. Prediction and validation of major gas and tar species from a reactor network model of air-blown fluidized bed biomass gasification. Energy E Fuels, 29(4):2437-2452, 2015.

[12] M. Corbetta, A. Bassani, F. Manenti, C. Pirola, E. Maggi, Pettinau A., P. Deiana, S. Pierucci, and E. Ranzi. Multi-scale kinetic modeling and experimental investigation of syngas production from coal gasification in updraft gasifiers. Energy $\mathcal{E}$ Fuels, 29(6):3972-3984, 2015.

[13] M. Frenklach, D.W. Clary, W.C. Gardiner Jr., and S.E. Stein. Detailed kinetic modeling of soot formation in shock-tube pyrolysis of acetylene. Symposium (International) on Combustion, 20(1):887-901, 1985. Twentieth Symposium (International) on Combustion.

[14] C.W. Bauschlicher Jr. and A. Ricca. Mechanisms for polycyclic aromatic hydrocarbon (pah) growth. Chemical Physics Letters, 326(3-4):283-287, 2000. 
[15] C.W. Bauschlicher Jr., A. Ricca, and M. Rosi. Mechanisms for the growth of polycyclic aromatic hydrocarbon (pah) cations. Chemical Physics Letters, 355(12):159-163, 2002.

[16] N Fuji and T Asaba. Shock-tube study of the reaction of rich mixtures of benzene and oxygen. In Proceedings of the Fourteenth Symposium (International) on Combustion, volume 14, pages 433-442, 1973.

[17] R.P. Lindstedt and K.A. Rizos. The formation and oxidation of aromatics in cyclopentene and methyl-cyclopentadiene mixtures. Proceedings of the Combustion Institute, 29(2):2291-2298, 2002.

[18] Jürgen Warnatz, Ulrich Maas, and Robert W Dibble. Combustion: physical and chemical fundamentals, modeling and simulation, experiments, pollutant formation. Springer, 2006.

[19] Kenneth K Kuo. Principles of combustion. Wiley New York, 2 edition, 2005.

[20] M Frenklach. On the driving force of pah production. Symposium (International) on Combustion, 22(1):1075-1082, 1989.

[21] T.E. McGrath, R. Sharma, and M.R. Hajaligol. An experimental investigation into the formation of polycyclic-aromatic hydrocarbons (pah) from pyrolysis of biomass materials. Fuel, 80(12):1787-1797, 2001.

[22] T.E. McGrath, W.G. Chan, and M.R. Hajaligol. Low temperature mechanism for the formation of polycyclic aromatic hydrocarbons from the pyrolysis of cellulose. Journal of Analytical and Applied Pyrolysis, 66(1-2):51-70, 2003.

[23] J.F. Davidson. The two-phase theory of fluidization: successes and opportunities. In AIChE Symposium Series, volume 87, pages 1-12, 1991.

[24] K Hilligardt and J. Werther. Gas flow in and around bubbles in gas fluidized beds-local measurements and modelling considerations. In Proceedings of World Congress II of Chemical Engineering, pages 429-432, 1986. 
[25] A. Hashemi Sohi, A. Eslami, A. Sheikhi, and R. Sotudeh-Gharebagh. Sequentialbased process modeling of natural gas combustion in a fluidized bed reactor. Energy $\mathcal{F}$ Fuels, 26(4):2058-2067, 2012.

[26] H. Asadi-Saghandi, R. Sotudeh-Gharebagh, A.M. Dashliborun, H. Kakooei, and M. Hajaghazadeh. Sequential-based process modelling of vocs photodegradation in fluidized beds. The Canadian Journal of Chemical Engineering, 92(11):1865$1874,2014$.

[27] A. Eslami, A. Hashemi Sohi, A. Sheikhi, and R. Sotudeh-Gharebagh. Sequential modeling of coal volatile combustion in fluidized bed reactors. Energy $\mathcal{F}$ Fuels, 26(8):5199-5209, 2012.

[28] F. Johnsson, S. Andersson, and B. Leckner. Expansion of a freely bubbling fluidized bed. Powder Technology, 68(2):117-123, 1991.

[29] S.P. Babu, B. Shah, and A. Talwalkar. Fluidization correlations for coal gasification materials-minimum fluidization velocity and fluidized bed expansion ratio. In AIChE Symp. Ser, volume 74, pages 176-186, 1978.

[30] A. Bakshi, C. Altantzis, R.B. Bates, and A.F. Ghoniem. Multiphase-flow statistics using $3 \mathrm{~d}$ detection and tracking algorithm (ms3data): Methodology and application to large-scale fluidized beds. Chemical Engineering Journal, 293:355-364, 2016.

[31] E. Ranzi, A. Cuoci, T. Faravelli, A. Frassoldati, G. Migliavacca, S. Pierucci, and S. Sommariva. Chemical kinetics of biomass pyrolysis. Energy E Fuels, 22(6):4292-4300, 2008.

[32] M. Calonaci, R. Grana, E.B. Hemings, G. Bozzano, M. Dente, and E. Ranzi. Comprehensive kinetic modeling study of bio-oil formation from fast pyrolysis of biomass. Energy $\mathcal{F}$ Fuels, 24(10):5727-5734, 2010.

[33] E. Ranzi, S. Pierucci, P.C. Aliprandi, and S. Stringa. Comprehensive and detailed kinetic model of a traveling grate combustor of biomass. Energy $\mathcal{F}$ Fuels, 25(9):4195-4205, 2011. 
[34] E Ranzi, M. Corbetta, F. Manenti, and S. Pierucci. Kinetic modeling of the thermal degradation and combustion of biomass. Chemical Engineering Science, 110:2-12, 2014.

[35] R.B. Bates, C. Altantzis, and A.F. Ghoniem. Modeling of biomass char gasification, combustion, and attrition kinetics in fluidized beds. Energy $\mathcal{F}$ Fuels, 30(1):360-376, 2016.

[36] David G. Goodwin, Harry K. Moffat, and Raymond L. Speth. Cantera: An objectoriented software toolkit for chemical kinetics, thermodynamics, and transport processes. http: //www. cantera. org, 2014. Version 2.1.2.

[37] D.J. Gunn. Transfer of heat or mass to particles in fixed and fluidised beds. International Journal of Heat and Mass Transfer, 21(4):467-476, 1978.

[38] A. Terzis, J. von Wolfersdorf, B. Weigand, and P. Ott. A method to visualise near wall fluid flow patterns using locally resolved heat transfer experiments. Experimental Thermal and Fluid Science, 60:223-230, 2015.

[39] D. Gidaspow. Multiphase Flow and Fluidization: Continuum and Kinetic Theory Descriptions. Academic Press, 1994.

[40] M. Syamlal, W. Rogers, and T.J. O'Brien. Mfix documentation theory guide. Technical report, U.S. Department of Energy, National Energy Technology Laboratory, 1993.

[41] M. Syamlal. Mfix documentation numerical technique. Technical report, U.S. Department of Energy, National Energy Technology Laboratory, 1998.

[42] C. Di Blasi and C. Branca. Kinetics of primary product formation from wood pyrolysis. Industrial E Engineering Chemistry Research, 40(23):5547-5556, 2001.

[43] Q. Xue and R.O. Fox. Multi-fluid cfd modeling of biomass gasification in polydisperse fluidized-bed gasifiers xue, q.; fox, ro. Powder Technology, 254:187-198, 2014. 
[44] Chan W.R., M. Kelbon, and B.B. Krieger. Modelling and experimental verification of physical and chemical processes during pyrolysis of a large biomass particle. Fuel, 64(11):1505-1513, 1985.

[45] P. C. Johnson and R. Jackson. Frictional-collisional constitutive relations for granular materials, with application to plane shearing. Journal of Fluid Mechanics, 176:67-93, 1987.

[46] S.V. Patankar. Numerical Heat Transfer and Fluid Flow. Hemisphere Publishing Corporation, 1980.

[47] T. Milne, R. J. Evans, and N. Abatzoglou. Biomass gasifier tars: Their nature, formation and conversion. Technical Report TP-570-25357, National Energy Technology Laboratory (NETL), 1998. 
